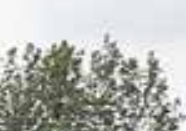

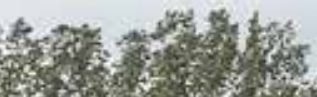

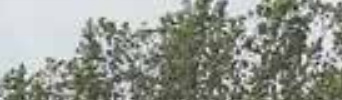

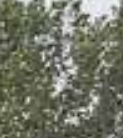

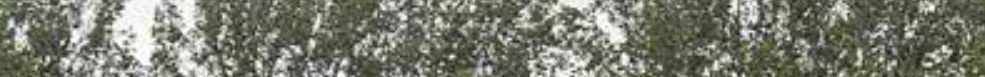
3.

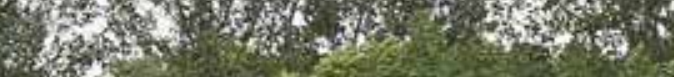

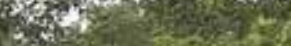
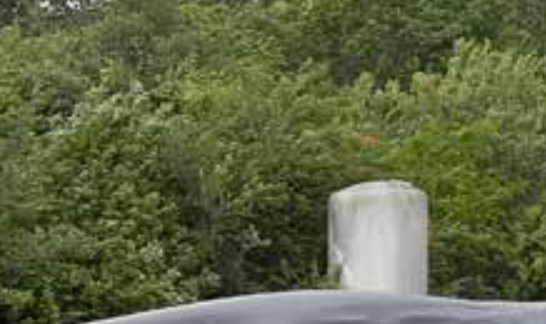

t.
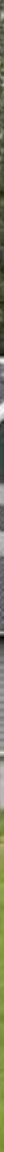

\title{
ESBL Evaluation framework
}

Nico Bondt, Marcel van Asseldonk, Ron Bergevoet

LE I

WAGENINGEN UR 


\section{ESBL Evaluation framework}

Nico Bondt, Marcel van Asseldonk, Ron Bergevoet

This study was carried out by LEI Wageningen UR and was commissioned and financed by the Dutch Ministry of Economic Affairs within the context of the 'ESBLs and intervention' (project number BO-20-016-001)

LEI Wageningen UR

Wageningen, July 2016

REPORT

LEI 2016-020

ISBN 978-94-6257-851-7 
Bondt, Nico, Marcel van Asseldonk, Ron Bergevoet, 2016. ESBL Evaluation framework. Wageningen, LEI Wageningen UR (University \& Research centre), LEI Report 2016-020. 46 pp.; 18 fig.; 2 tab.; 37 ref.

Extended-spectrum bèta-lactamases (ESBL)-producing bacteria have become increasingly common in animals and humans. The goal of the presented ESBL evaluation framework is to help policy makers to evaluate the effectiveness of possible interventions aimed to reduce ESBL levels in livestock. An objective-driven ESBL policy approach (i.e., setting more clear and stringent objectives, for example maximum ESBL prevalence on national level) is preferable since much is unknown about other potential relevant measures and moreover the accountability of individual agents is hampered, which are both requisites for a measure-driven policy approach. In addition, for the nearby future, an additional measure is to extend the ban on some other antibiotics that are related to ESBLs.

This report can be downloaded for free at http://dx.doi.org/10.18174/385287 or at www. wageningenUR.nl/en/lei (under LEI publications).

\section{(C) 2016 LEI Wageningen UR}

P.O. Box 29703, 2502 LS The Hague, The Netherlands, T +31 (0)7033583 30,

E informatie.lei@wur.nl, www.wageningenUR.nl/en/lei. LEI is part of Wageningen UR (University \& Research centre).

\section{(cc) BY-NC}

For its reports, LEI utilises a Creative Commons Attributions 3.0 Netherlands license.

(c) LEI, part of DLO Foundation, 2016

The user may reproduce, distribute and share this work and make derivative works from it. Material by third parties which is used in the work and which are subject to intellectual property rights may not be used without prior permission from the relevant third party. The user must attribute the work by stating the name indicated by the author or licensor but may not do this in such a way as to create the impression that the author/licensor endorses the use of the work or the work of the user. The user may not use the work for commercial purposes.

LEI accepts no liability for any damage resulting from the use of the results of this study or the application of the advice contained in it.

LEI is ISO 9001:2008 certified.

LEI 2016-020 | Project code 2273000576

Cover photo: Fred van Welie/Wageningen UR 


\section{Contents}

$\begin{array}{ll}\text { Preface } & 5\end{array}$

$\begin{array}{ll}\text { Summary } & 6\end{array}$

S.1 Key findings $\quad 6$

S.2 Complementary findings $\quad 6$

$\begin{array}{lll}\text { S.3 Method } & 7\end{array}$

\begin{tabular}{l|l}
1 & $\mathbf{1}$ ntroduction
\end{tabular}

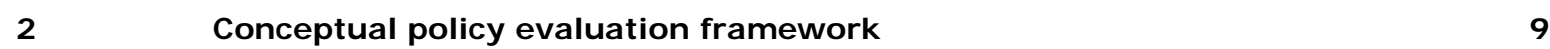

$3 \quad$ Policy decisions for human health risks and animal welfare 13

$\begin{array}{lll}3.1 & \text { Q-fever eradication programme } & 13\end{array}$

3.2 Salmonella Se/St eradication programme $\quad 15$

$\begin{array}{lll}3.3 & \text { Implementing quality programmes } & 18\end{array}$

$\begin{array}{ll}3.4 & \text { Veterinary use of antibiotics }\end{array}$

$\begin{array}{lll}3.5 & \text { Animal welfare } & 25\end{array}$

$\begin{array}{lll}3.6 & \text { Ammonia emissions } & 27\end{array}$

3.7 Lessons learned from previous intervention programmes 30

$\begin{array}{lll}3.8 & \text { Revised framework } & 31\end{array}$

$4 \quad$ Policy decisions for ESBL $\quad 33$

4.1 Past and presence policy decisions ESBL 33

4.1.1 Objectives 33

4.1.2 Measures 33

$\begin{array}{ll}4.1 .3 \text { Agents } & 34\end{array}$

4.1.4 Socio-economic context 34

$\begin{array}{lll}4.1 .5 & \text { Results } & 35\end{array}$

4.2 Recommendations future policy decisions ESBL 36

4.2.1 Current realisation of policy objectives 36

4.2.2 Objective-driven or measure-driven approach 36

4.2.3 Sense of urgency policy makers $\quad 37$

4.2.4 Availability of effective measures $\quad 37$

4.2.5 Accountability of the individual agent 39

$\begin{array}{ll}4.2 .6 \text { Agent } & 40\end{array}$

4.2.7 Socio-economic context $\quad 40$

$5 \quad$ Conclusion and discussion

41

$\begin{array}{lll}5.1 & \text { General evaluation framework } & 41\end{array}$

$\begin{array}{lll}5.2 & \text { ESBL evaluation framework } & 42\end{array}$

$\begin{array}{ll}\text { References and websites } & 43\end{array}$ 



\section{Preface}

Extended-spectrum beta-lactamase (ESBL)-producing and AmpC Beta-lactamase (AmpC)-producing bacteria have been found in increasing numbers in humans and animals since 2000 . To reduce the risk of human infections by farm animals, it is important to reduce the number of ESBL- and/or AmpCproducing bacteria in farm animals. To achieve this, more knowlegde is needed about interventions that can be used to reduce these numbers.

As part of a research grant from the Ministry of Economic Affairs, LEI Wageningen UR analysed an ESBL (AmpC) evaluation framework to help policy makers to evaluate the effectiveness of possible interventions aimed to reduce ESBL levels in livestock. An objective-driven ESBL policy approach (i.e., setting more clear and stringent objectives, for example maximum ESBL prevalence on national level) is preferable since much is unknown about other potential relevant measures and moreover the accountability of individual agents is hampered, which are both requisites for a measure-driven policy approach. In addition, for the nearby future, an additional measure is to extend the ban on some other antibiotics that are related to ESBLs.

We would like to thank CVI, the steering committee, and the experts consulted for their constructive comments and excellent guidance and advice throughout the entire period of this study.

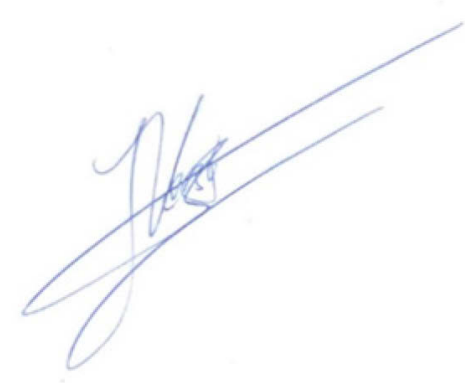

Prof.dr.ir. Jack G.A.J . van der Vorst

General Director Social Sciences Group - Wageningen UR 


\section{Summary}

\section{S.1 Key findings}

Extended-spectrum bèta-lactamases (ESBL)-producing bacteria have become increasingly common in animals and humans. The goal of the presented ESBL evaluation framework is to help policy makers to evaluate the effectiveness of possible interventions aimed to reduce ESBL levels in livestock.

An objective-driven ESBL policy approach (i.e., setting more clear and stringent objectives, for example maximum ESBL prevalence on national level) is preferable since much is unknown about other potential relevant measures and moreover the accountability of individual agents is hampered, which are both requisites for a measure-driven policy approach.

In addition, for the nearby future, setting a few additional measures seems to be appropriate too. The most prominent additional measure is to extend the ban on some other antibiotics that are related to ESBLs. Indirectly, a more stringent target for the reduction of veterinary antibiotic use could also support the ESBL-reducing objective. The advantage of a target on antibiotic use is that individual agents can be held accountable.

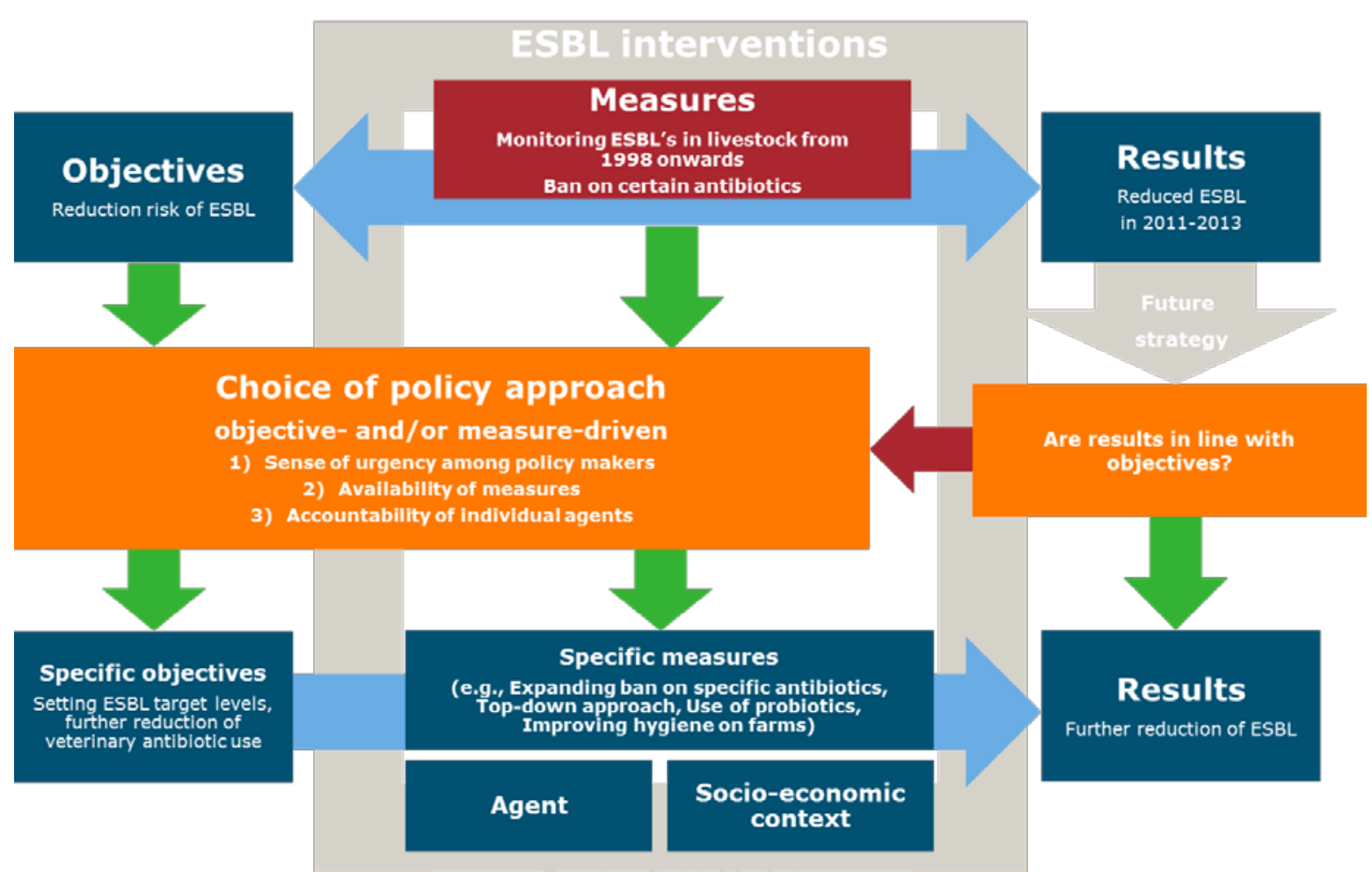

Figure S.1 ESBL interventions within the evaluation framework.

\section{S.2 Complementary findings}

The effectiveness of the policy largely depends on the agents and the socio-economic context. Different interventions will probably be needed for different agents e.g. groups of farmers and other relevant stakeholders, depending on each group's specific socio-economic context. Not all measures 
are equally suitable to be implemented by all stakeholders, and the effectiveness of the implementation partly depends on stakeholders' socio-economic environment and circumstances. Motivating farmers on implementing behaviour aiming to maintain and preserve public goods most likely needs a different approach than motivating farmers in cases in which they perceive direct benefits.

\section{S.3 Method}

To support policy making and to gain insight into the different mechanisms that lead to a successful intervention a conceptual framework was developed and applied for several relevant cases. The model was validated with cases that address human health risks or animal welfare issues in terms of objectives and measures taken. The case description is based on the review of literature and reports published on the cases, and interviews with experts. Subsequently, ESBL policy choices for the coming years by using the evaluation framework and suggestions for further research are analysed. 


\section{Introduction}

\section{ESBLS}

Extended-spectrum bèta-lactamases (ESBL)-producing bacteria ${ }^{1}$ have become increasingly common in animals and humans since 2000. For example, in 2009 almost 100\% of Dutch broiler farms, 50\% of the veal calf farms and $40 \%$ of the pig farms are ESBL positive. More recently, prevalence of ESBLs in livestock has reduced as a consequence of reducing veterinary antibiotic use (MARAN, 2015). Prevalence in livestock farmers is also relatively high. In Dierikx (2013), for example, 33\% of the broiler farmers were tested positive.

Knowledge on specific impacts of ESBL on human health is fragmented. An ESBL prevalence of $4.9 \%$ has been found in Dutch hospital patients in the province with the highest number of broiler chickens (Huijbers, 2013). In Europe, it is estimated that around 25,000 patients die annually as a result of infections caused by resistant bacteria (without specifying the attribution of ESBL of animal origin). This translates into estimated costs of $1.5 \mathrm{bn}$ euros per annum, due to loss of productivity and an increase in healthcare expenditures (DG Sante, 2015).

The environment and food are two possible transmission routes by which humans can be exposed to ESBLs from animal sources, yet much is unknown on the level of attribution. Exposure through the environment results from (direct or indirect) contact with infected livestock. Exposure through food results from consuming or handling contaminated animal products.

Resistant ESBL-producing bacteria can harm the effectiveness of antibiotics in human medicine. This has led to increased interest in potential interventions to reduce the ESBLs in livestock. More insight into potential and effective interventions is needed to be able to reduce the human exposure to ESBLS originating from livestock. Adoption of effective interventions inevitably consist of changing the present behaviour of farmers and other major stakeholders in the livestock sector.

\section{Outline}

The goal of the ESBL evaluation framework is to help policy makers to evaluate the effectiveness of possible interventions aimed to reduce ESBL levels in livestock in the Netherlands. The epidemiological effectiveness of measures is only briefly mentioned since that is addressed and elaborated on by researchers of the Central Veterinary Institute during present and future research.

To gain insight into the different mechanisms that lead to a successful intervention, a conceptual framework was developed (Chapter 2) and applied for several relevant cases. Since reports of effective ESBL intervention strategies are lacking, we analyse cases that address human health risks or animal welfare issues in terms of objectives and measures taken. The case description is based on the review of literature and reports published on the cases, and interviews with experts (Chapter 3). Chapter 4 then focuses on ESBL with respect to current objectives, the socio-economic context, the agents involved, and the relation between aforementioned issues and interventions. Moreover, the policy choices for the coming years by using the evaluation framework and suggestions for further research are presented. Finally, in Chapter 5, conclusions are drawn on both the general and ESBL evaluation framework.

\footnotetext{
${ }^{1}$ Although we focus on ESBL-producing bacteria, the findings presented in this report also hold for AmpC bèta-lactamases (AmpC)-producing bacteria.
} 


\section{Conceptual policy evaluation framework}

\section{Objectives}

Formulating a policy strategy starts with the question if the impacts are in line with the current policy objectives. If the results are not satisfactory, an adjustment of the policy is needed. The next step is to choose between an objective-driven or measure-driven approach or a hybrid approach. One way forward is to start with implementing an incentive system to realise the objectives in the livestock chain (e.g., bonus for low prevalence level and/or malus for high prevalence level). These incentives will stimulate farmers to take appropriate measures (e.g., the use of probiotics, reduction of antibiotic use, or adoption of more stringent levels of hygiene and biosecurity). Farmers decide for themselves which measure(s) they prefer and implement. Alternatively, the intervention can focus on specific measures that can be made mandatory by a regulator or encouraged by, for example, subsidies.

\section{Measures and interventions}

In this memorandum we distinguish between 'measures' and 'interventions'. 'Measures' are defined as technical activities and management choices by operators in the food supply chain (e.g. feeding probiotics by farmers) to reduce ESBL prevalence and transmission. Measures thus focus on the ESBLs. 'Interventions' are defined as activities that stimulate and support implementing measures. Considering this, interventions focus on the agents involved in taking measures. A measure is then always part of an intervention. Interventions are a set of one or more measures combined with activities aimed at implementation, and that often require a multidisciplinary approach (Figure 2.1). A successful intervention consists of a combination of measures and activities suited to the particular socio-economic context to facilitate adoption of the measures by agents.

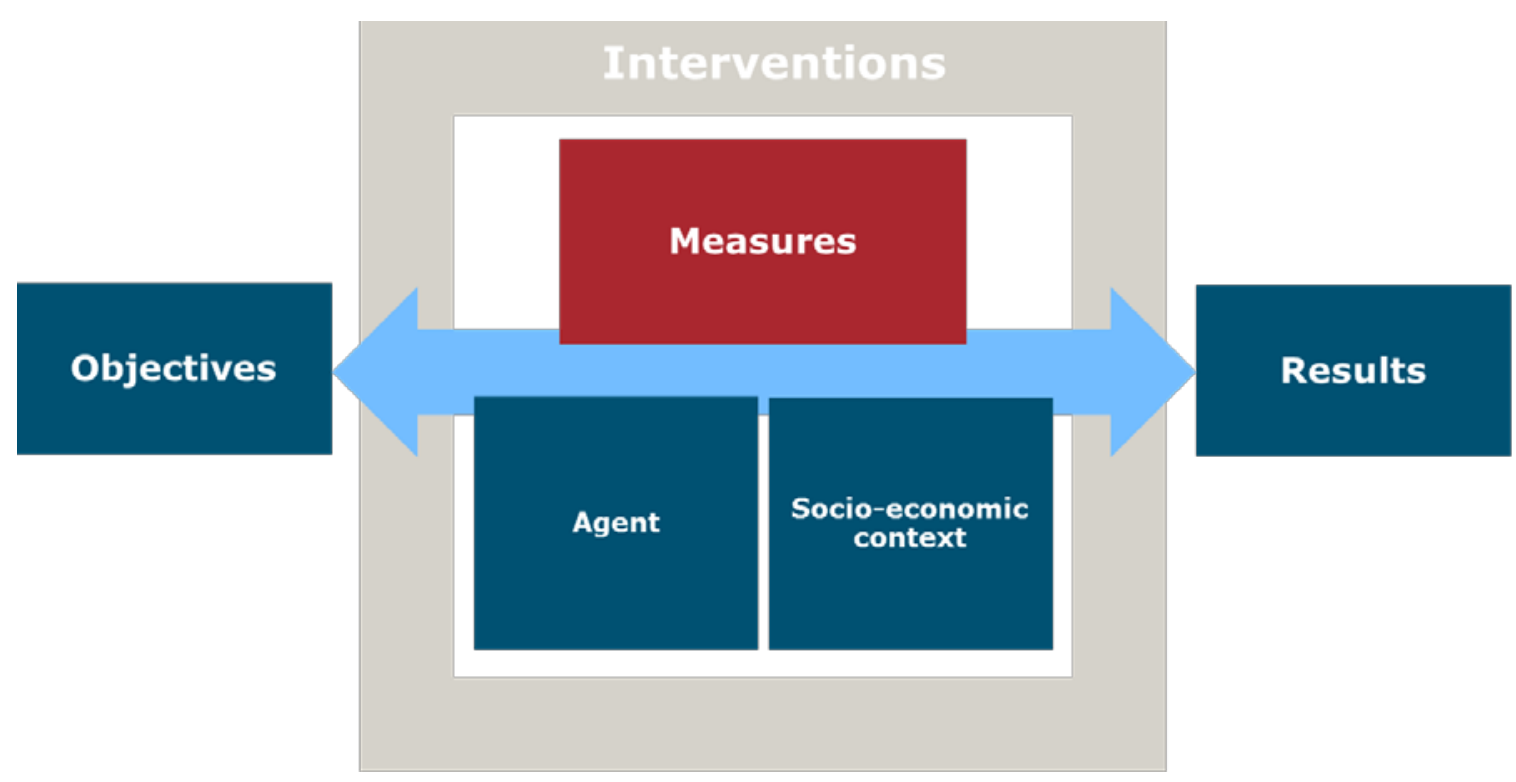

Figure 2.1 General approach of the ESBL evaluation framework.

\section{Socio-economic context}

The following analysis of the socio-economic context aims to analyse the possible contextual dependency between measures and expected results. Figure 2.2 shows the key factors in the socioeconomic context. The socio-economic contextual factors focus on the agent (i.e., actor), sector and society. 


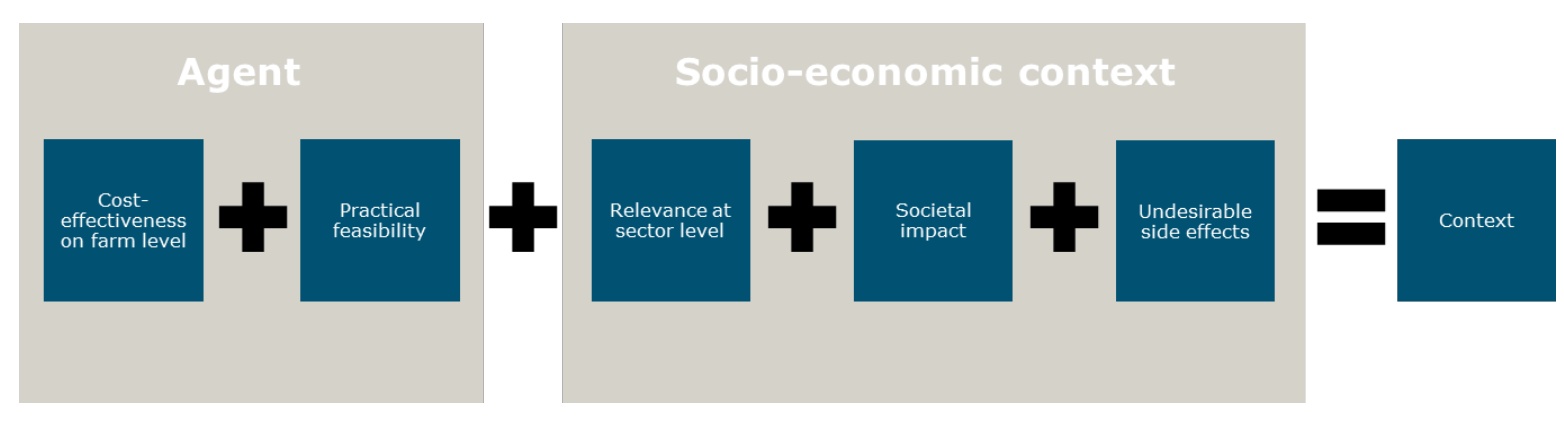

Figure 2.2 Societal-contextual factors.

To simplify the problem we assume that agents (i.e., livestock farmer) mainly make intervention decisions based on the cost-effectiveness and practical feasibility.

- Cost-effectiveness

Many studies show that the cost of implementing a measure crucially influences the farmer's actual behaviour. Most farmers will take an expensive measure only if the expected revenues outweigh costs, or if the measure is important for another reason.

- Practical (and technical) feasibility

In addition to costs, a measure's practical feasibility is also important to consider. Even a costeffective measure will not be taken if it requires too much time, effort or both. Moreover, if the measure requires special skills or techniques that the farmer might not have yet or are not available yet, this might hamper the farmer in adopting the measure. Legislative limitations or required licenses are other relevant aspects hindering feasibility.

Complementary factors need to be accounted for at a more aggregated level (i.e., livestock sector or society as a whole). The likelihood of implementation is approximated by three socio-economic contextual factors: relevance at sector level, societal impact, and undesirable side-effects.

- Relevance at sector level

The impact of applying a specific measure is influenced by the current level of implementation. If the measure has already been implemented by most farmers, the additional impact on sector level will be small. Nevertheless, the measure in itself may still be effective and can be part of an intervention (Breukers et al., 2013). Moreover, measures can be costly for individual farmers but the results can be important to the sector as a whole (for example to brand food safety or to prevent export bans).

- Societal impact

The measures taken have to be acceptable from a societal point of view. Measures with an overall positive societal impact are preferable. The focus is not only on the costs and benefits that can be expressed in monetary terms, but also on the costs and benefits that have not (or not yet) been expressed in monetary terms, such as the environment, food safety and nature. For example, in terms of human health improvement, the revenues of the measures could be quantified in DALYS and QALYs averted (Bogaardt et al., 2004).

- Undesirable side effects

The preferred measures will need to have little or no negative impact on other important aspects, such as animal welfare or the environment.

\section{Agents}

For developing successful interventions, it is important to obtain more insight into the behaviour of agents (i.e., farmers and other relevant stakeholders) towards possible measures, and to understand why agents do or do not behave as expected on the basis of purely rational grounds within the prevailing socio-economic context as described in the previous section. Multiple theories exist that try to describe human behaviour and factors that influence this behaviour. A categorisation of these theories is to separate them into theories that describe intentional behaviour and unintentional behaviour.

The adoption of technical measures in a socio-economic context can best be described as an intentional behavioural change. A theory often used to describe intentional behaviour is the Theory of Planned Behaviour (TPB) (Ajzen, 1991), which can give valuable insights into the personal 
characteristics of the actors that might influence the behavioural change. This theory states that a person's intention to perform a behaviour is predominantly driven by three determinants:

- Attitude

The personal favourable or unfavourable evaluation of taking the specific measure: an individual's personal motivation, expectations and perceived importance of the measure. The motivation will also be influenced by the perceived relationship between the measure and the objective (Ypma and Van Gaasbeek, 2001).

- Subjective norm

The social pressure to take measures, determined by perceived expectations from others and their importance. This determinant is not about legal obligations, but it can be influenced by the social pressure that is related to regulation.

- Perceived behavioural control

Does the person expect to be able to take the intended measures? The ability includes both selfefficacy (i.e., having the means and skills perceived necessary to perform the behaviour) and controllability (i.e., the level to which an individual experiences full control over his behaviour).

In summary, behavioural intention is determined by the extent to which a person considers oneself willing, pressed, and able to take the intended measures.

The Theory of Planned Behaviour has been proven to be successful in different domains, including the agricultural domain (Beedell en Rehman, 2000; Bergevoet et al., 2004; Colémont en Van den Broucke, 2008; Fielding et al., 2008; De Lauwere et al., 2012; Breukers et al., 2012).

Based on the insights obtained from behavioural analysis, interventions can be developed to facilitate the adoption of relevant measures (Breukers et al., 2012; Breukers et al., 2013). To facilitate the adoption of the measures the limiting factors need to be addressed within the socio-economic context. Each limiting factor often requires a specific intervention method, as illustrated in Figure 2.3.

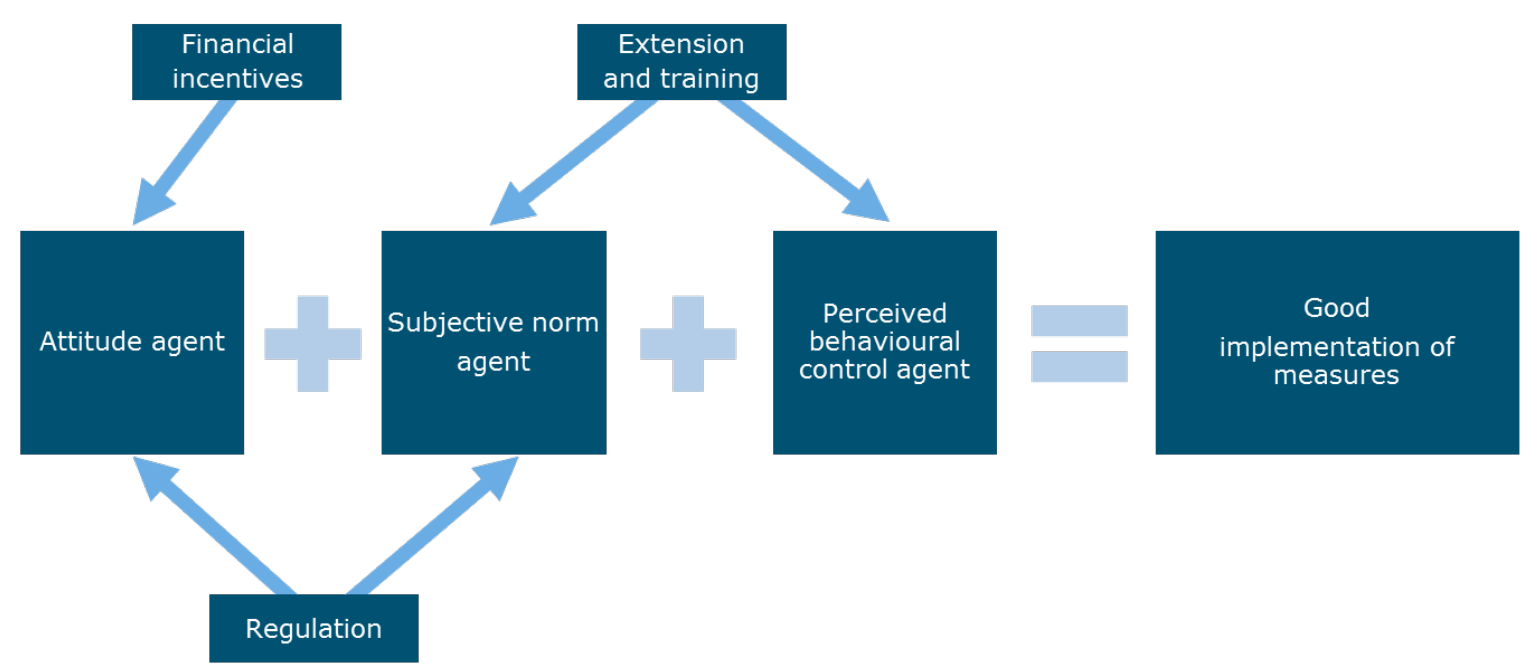

Figure 2.3 Example of relation between interventions and behavioural characteristics of the agent.

For example, an extension and training course is effective to solve the problem of insufficient skills (i.e., to increase perceived behavioural control) and may affect the subjective norms, but it will be less effective to improve the agent's attitude (i.e., to increase motivation). While financial incentives set by the industry or by a regulator will motivate the agent to adopt an intervention. Regulation and compliance with legislation will target agents and motivate them to adopt interventions. Moreover, the extent to which the community disapproves or approves of the violating behaviour will affect social control and thus the subjective norm (Dutch Ministry of Justice, 2004). 
The short-list of five societal-contextual factors and three determinants affecting the agent's intention are selected because they can all be applied relatively easily in the field of policy-making. To validate this evaluation framework, a further analysis of relevant cases is nevertheless required. 


\section{Policy decisions for human health risks and animal welfare}

Intervention strategies to control human health risks related to livestock as well as strategies to improve animal welfare in the past focused either on the adoption of concrete measures, or on the overall objective of the control programme. In the latter case, stakeholders were enabled to choose measures to be implemented themselves. The following cases were selected: Q-fever eradication programme from 2008 to 2011, Salmonella Se/St eradication programme from 1997 onwards, implementing quality programmes from the 1990s onwards, veterinarian antibiotic reduction programme from 2000 onwards, animal welfare programme from 2012 onwards, and the environmental emission reduction programme from 1996 onwards. For each case the evaluation framework is applied and the corresponding problem, objectives, measures, socio-economic context, agent and results achieved is elaborated on.

\subsection{Q-fever eradication programme}

\section{Problem}

Q fever has become a major public health concern in the Netherlands, with a peak of notified human Q-fever cases in 2009 (Schimmer et al., 2009; Hoek et al., 2010). Abortion waves of dairy goats were the primary source of infection for humans living near infected dairy goat farms (Hoek et al., 2010). According to RIVM statistics, the total number of notified human Q-fever cases amounted to 4,107 individuals, of which 19 died. Q fever can cause chronic Q-fever illness or chronic fatigue syndrome, either following an acute infection, but also after mild flu-like symptoms or even without showing symptoms. Besides abortions, additional losses on dairy goat farms from reduced milk production, mortality and weight loss were limited (Van Asseldonk et al., 2013).

\section{Evaluation based on the framework}

\section{Objectives of the programme}

In the Netherlands, in June 2008, Q fever became notifiable for small ruminants kept for milk production (Roest et al., 2011). The public health objective was to control the Q-fever infection, thereby minimising human health costs and disease burden (Figure 3.1). The severe human health issues were the main driving forces to follow a stringent set of measures to control Q fever.

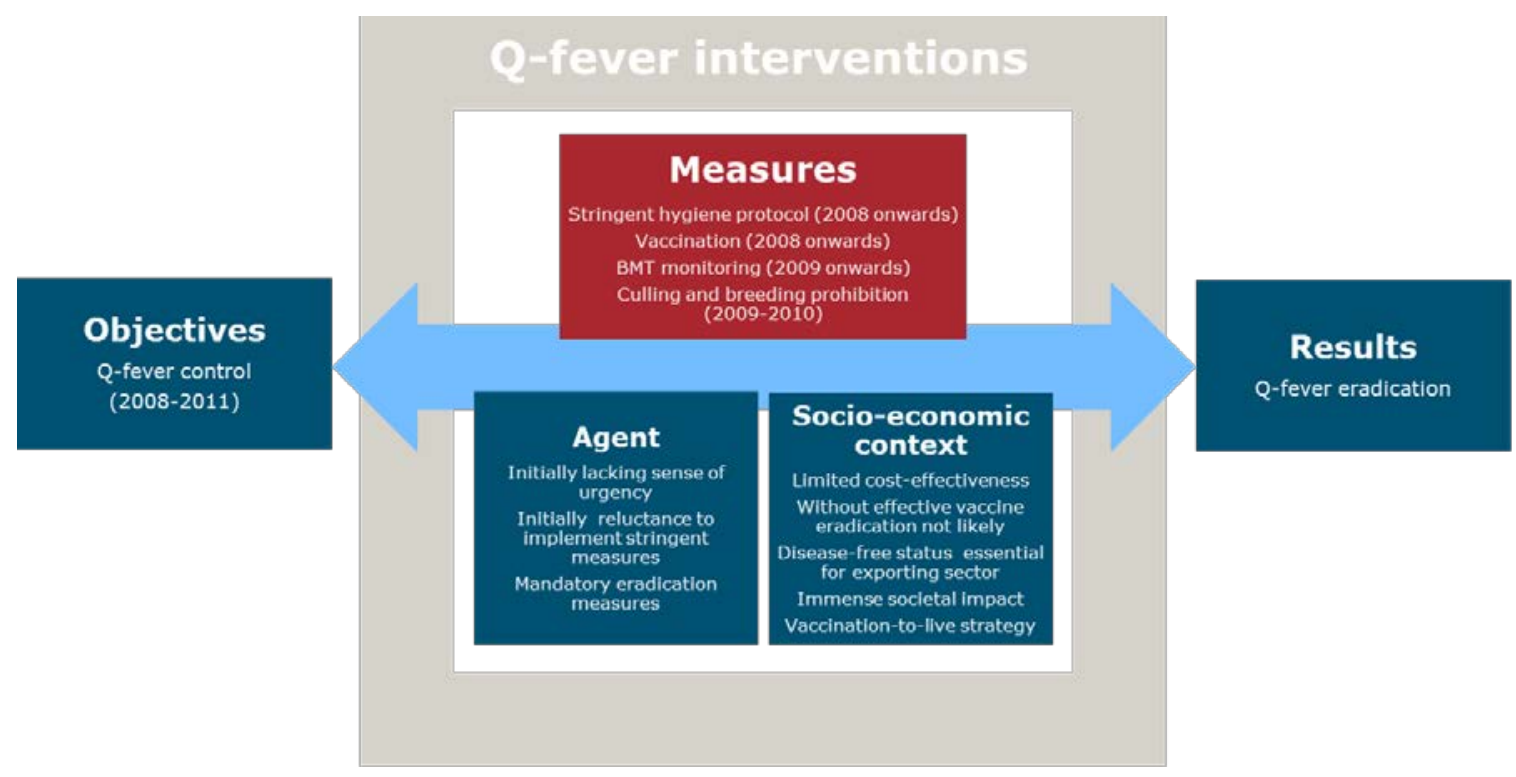

Figure 3.1 Q-fever interventions within the evaluation framework. 


\section{Measures implemented}

From 2008 onwards several complementary measures were taken to control the disease. First a stringent hygiene protocol was made mandatory for all professional dairy goat and dairy sheep farms. In 2008 a voluntary vaccination campaign started that became mandatory in high-risk areas in 2009. In addition, a transport ban of animals and a visitor ban was issued for all Q-fever positive farms. To curb the epidemic, the control had to change from a risk-based approach to the precautionary principle (Bruschke et al., 2015). A national television broadcast on 6 December 2009 became a tipping point: it placed the issue more urgently on the national political agenda. The livestock sector was not making enough progress in controlling the disease and the pressure from human health sector became intense, so the government was forced to take firm and immediate action. Taking obligatory measures seemed obvious. From December 2009 up to 2010 all pregnant goats and sheep were culled on Q-fever positive farms (Hogerwerf et al., 2011; Roest et al., 2011). A breeding prohibition period on infected farms was enforced at farms with more than 50 dairy goats (or dairy sheep). From 2009/2010 onwards vaccination became mandatory on dairy goat and dairy sheep farms with more than 50 animals and on petting zoos. Finally, a rigorous surveillance procedure is followed where bulk milk samples are tested. Both compulsory vaccination as well as testing of bulk milk samples are continued.

\section{Agents}

- Attitude/Subjective norm

Although Q fever was a relatively obvious and tangible problem, the sense of urgency was initially lacking and agents (i.e., farmers) were reluctant to implement stringent measures on a voluntary basis. I nitially, also the competent authority was not willing to launch a culling campaign. The stringent control protocol was made mandatory for all professional dairy goat and dairy sheep farms once the size of the outbreak became evident.

The competent authority accompanied enforcement with reimbursement of affected farmers. Since the regulation was strictly enforced for the whole sector the attitude and subjective norm of individual farmers is of less relevance.

- Perceived behavioural control

This was not a barrier, because vaccination was administered by veterinarians, who have all the necessary skills.

\section{Socio-economic context}

- Cost-effectiveness at farm level

The cost-effectiveness at farm level is limited since the potential benefits of implementing control measures on farm level are marginal. In general the costs exceed the benefits. At sector level, the estimated public compensation for culled animals was approximately $19 \mathrm{~m}$ euros, while the government financed in total $55 \mathrm{~m}$ euros for incurred costs in the livestock sector (Tempelman et al., 2011).

- Practical and technical feasibility

Most of the measures could be implemented fairly easily. However, to a certain extent the breeding ban and transport ban hampered ongoing farming activities. Moreover, a number of measures to reduce the spread of infectious material, such as restrictions in spreading manure and covering of manure heaps, were valued as not practical to implement by the livestock sector. Without the certainty that the available vaccine was effective, eradication would be seriously hampered and one had to resort to a mass culling strategy.

- Relevance at sector level Vaccination or culling are both relevant and effective measures to control Q fever at sector level (Bontje et al., 2013). In the future, the animal health fund for sheep and goats will reimburse a part of the incurred Q-fever losses on farms. ${ }^{2}$

\footnotetext{
${ }^{2}$ The animal health fund is a statutory levy system financed by the sector themselves in the Netherlands (Meuwissen et al., 2003). The government acts as a lender of last resort by indemnifying only excessive epidemics, while relatively minor losses are borne by the livestock sector in case of a new outbreak. The cost for ongoing monitoring are paid by the government and the levy fund whereby each pay half.
} 


\section{- Societal impact}

The societal impact of $\mathrm{Q}$ fever in affected areas is profound. Although almost all benefits are in the human health domain, the intervention costs were mostly incurred by the farming sector and will continue when the annual preventive vaccination and monitoring programme is enforced.

- Undesirable side effects

Animal welfare issues related to the culling of healthy pregnant goats and sheep on Q-fever positive farms, did not cause public debate during the first years of the eradication programme. Public resistance against the large-scale culling of animals was not massive. In general, the continued programme by means of a vaccination-to-live policy is, from an ethical point of view, preferred over a culling strategy (as vaccination-to-live is also the preferred strategy over large-scale preventive culling in the contingency plan for foot-and-mouth disease and classical swine fever in the Netherlands).

\section{Results}

By culling of infected animals, breeding prohibition and vaccination, the epidemic seems to be under control (Figure 3.2). The number of infected herds and humans as of July 2015 amounts to 5 and 12 respectively. As the dairy goat vaccination programme continues, future expenses in maintaining the current protected status are expected to be relatively low.

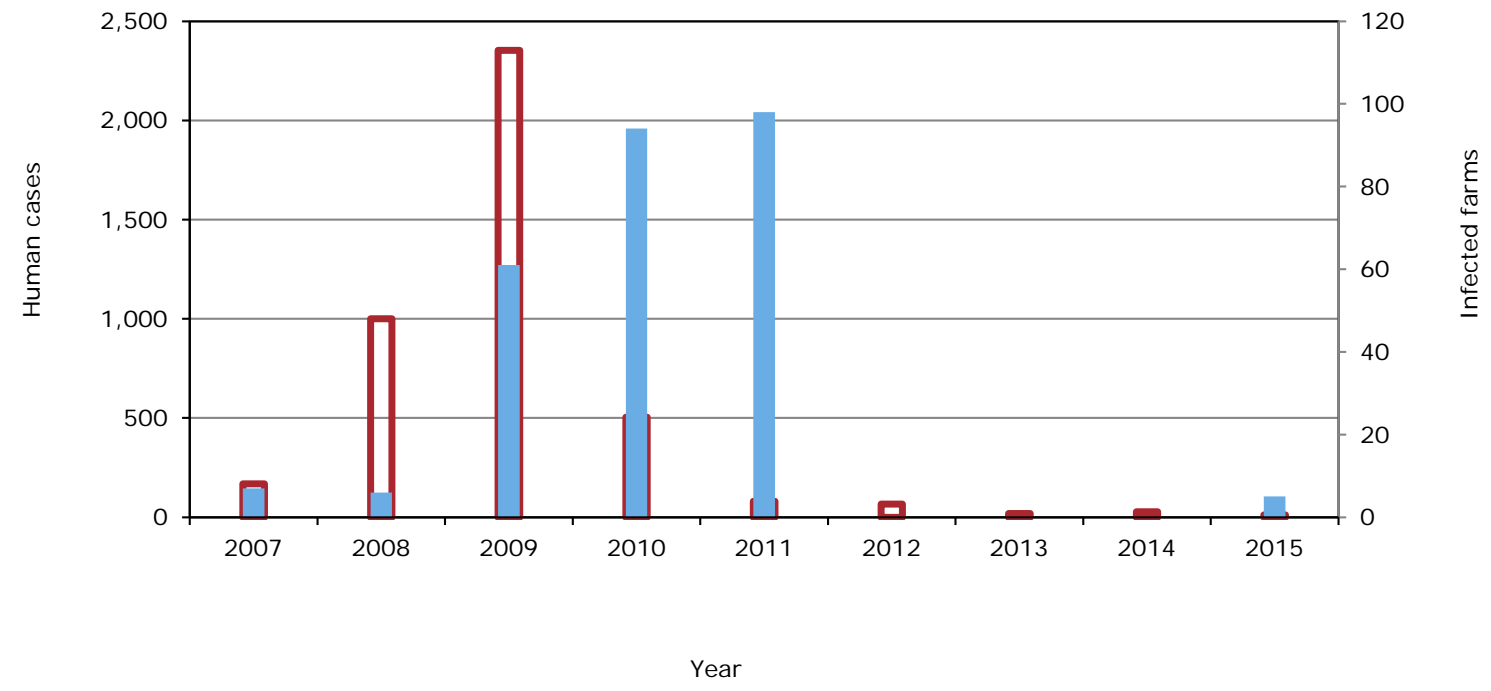

DHuman Cases $\quad$ Infected farms (observations 2012-2014 missing)

Figure 3.2 Results of policy decisions with respect to Q-fever control ${ }^{1}$ (www. rivm.nl).

\subsection{Salmonella Se/St eradication programme}

\section{Problem}

Salmonellosis is one of the most frequent food-borne infections. Eggs as well as poultry meat can be a source of human infection. The occurrence of Salmonella Enteritidis (Se) and Salmonella Thyphimurium (St) in the poultry sector is therefore a major public health concern. In the remainder of this high-level cases analysis, we will focus on the laying hen sector. In 1998, $11.6 \%$ of the laying hen flocks were infected with Se or St (PVE, 2012). To eradicate the presence of Se and St in eggs, an eradication programme in the laying as well as in the broiler sector was implemented in 1998. 


\section{Evaluation based on the framework}

\section{Objectives of the programme}

The objective was to reduce Salmonella prevalence at farm level, and other parts of the production chain, to avoid the potential hazard of Salmonella-contaminated products for public health (Figure 3.3). The private sector took the initiative to improve their consumer and customer value. The objective was that less than $5 \%$ of the laying hen flocks would be colonised with Se or St.

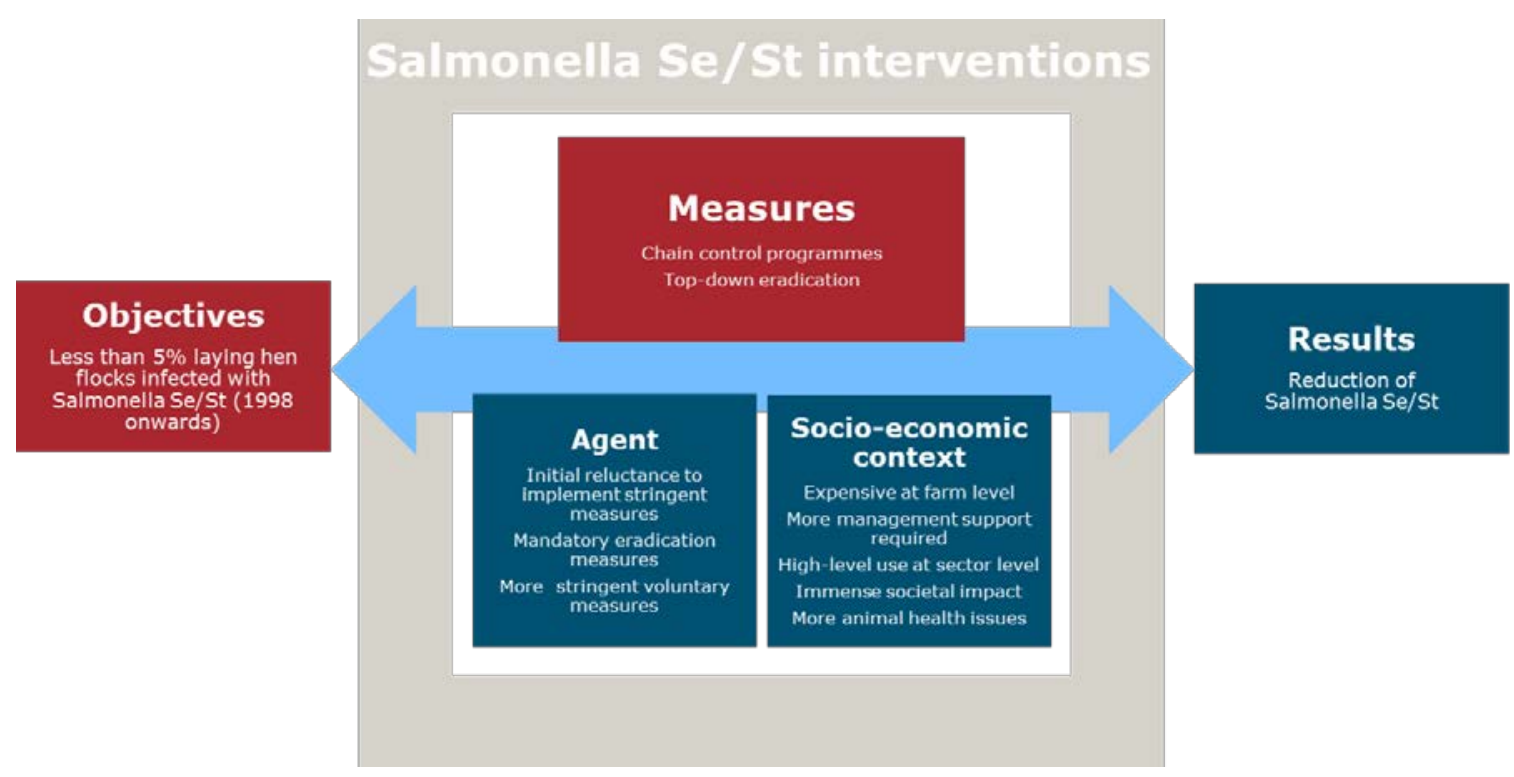

Figure 3.3 Salmonella interventions within the evaluation framework.

\section{Measures}

Environmental factors can play a very important role in the introduction of Salmonella infections. Strict hygiene measures, optimal sanitary and veterinary conditions are very important tools for prevention of any infectious agent including all Salmonella serotypes. Only a comprehensive package of hygiene and other preventive measures can considerably reduce the risk of introduction and transmission of Salmonella. The Dutch Commodity Board for Poultry and Eggs has developed the Integral Chain Control and Salmonella Control (ICCSC). This programme includes a system of business-oriented hygiene measures aimed at reducing the overall threat of microbial infection, including infection by salmonella, and specific prevention and control of contamination by Se and St.

The control plan to reduce Se and St prevalence was launched by the poultry sector in 1998 (PPE, ANEVEI, NOP and NVP). At the end of 2000 , the targeted maximum prevalence level was not met and a revised and more rigorous control plan was set-up. At first the Netherlands was a front runner, but later most other EU member states followed the same route. Since the targeted maximum prevalence level was not met a revised and more strict control plan was set-up (for example microflora preparations were too expensive and difficult to be implemented).

In addition, to control Salmonella transmission a top-down approach was applied by culling all contaminated (grant) parent flocks. This strategy is effective in the cases of Se and St infection in which infection can be transmitted through vertical transmission. ${ }^{3}$

\footnotetext{
3 Initially, antibiotics (enrofloxacin) and microflora preparations could be used for decontamination of infected breeding flocks. However, this treatment is by itself not $100 \%$ effective. In case this treatment was not effective contaminated animals and hatching eggs were removed. In 2002 Salmonella control regulations changed. Treatment was not allowed anymore and the animals had to be slaughtered after the first detection of Se or St.
} 
Additional control strategies were implemented by other stakeholders involved in the productions chain. For example, hatcheries improved and invested in their operation to prevent cross contamination.

\section{Agents}

- Attitude

Top-down eradication of Se and St was made mandatory in the Netherlands and strictly enforced.

- Subjective norm/Perceived behavioural control

The other measures are only compulsory for farm businesses that wish to participate in the ICCSC system. Participation in this ICCSC system is voluntary. By fulfilling all requirements a farm guarantees that it is doing everything that can reasonably be expected in order to realise an optimal Salmonella control. By now all farmers are within an ICCsc system (because of the pressure of the value chain): one can deduct that farmers have the skills to adopt the measures.

\section{Socio-economic context}

- Cost-effectiveness on farm level

At the moment, a full restitution to the farmers for the direct costs of eradication is foreseen. Although direct losses arising from the compulsory slaughter of birds infected with Se/St are financed from various resources (e.g. EU, Dutch Animal Health Fund), consequential losses are not eligible for compensation.

- Practical and technical feasibility The top-down control strategy could be implemented by the poultry sector.

- Relevance at sector level The measure was implemented at sector level. Although the poultry sector is a co-ordinated chain, a specific Se/St top-down control programme did not exist yet.

A disease-free status is of eminent importance for a sector that is export oriented. Farm businesses had to find private market-based solutions to manage these risks since there was no governmental compensation for consequential losses due to business interruption. Therefore the Avipol mutual insurance scheme has been developed to offer coverage against the risk of salmonella outbreaks (Se and St) in the rearing and breeding stages (Meuwissen et al., 2013). 'During the period from 1996 to 2001 when treatment was allowed, the Avipol mutual covered the cost of treatment. The Avipol has been launched in the Netherlands in 1996 applying deductibles and strict underwriting criteria (requiring certificates such as Integrated Chain Management and Salmonella Control) for farmers willing to participate in the mutual scheme. Currently, Avipol covers, among others, consequential losses in case of Se/St eradication. Since 2001, in addition to Se/St, the insurance coverage of other exotic Salmonella serotypes is also part of the Avipol policy.

- Societal impact

The societal impact of Salmonella infections is profound. Together with Campylobacter and Toxoplasma infections, these pathogens cause the highest disease burden and cost-of-illness of all food-borne pathogens. With an estimated disease burden in 2012 of 1,215 DALYs (Disability Adjusted Live Years) and an estimated cost-of-illness of nearly $22 \mathrm{~m}$ euros per year, Salmonella infections are a serious public health and socio-economic problem in the Netherlands (Bouwknegt al., 2015). Infections through Salmonella contaminated chicken meat and eggs are still responsible for a substantial amount of all human Salmonellosis.

- Undesirable side effects Animal welfare issues, such as culling of breeding flocks were less relevant during the first years of the eradication programme. In the long run, a disease-free status without emergency culling is preferred from an ethical point of view.

\section{Results}

The combined top-down approach and quality programmes have considerably reduced prevalence of Se and St over time (Figure 3.4). As an indication, in 2011 less than 1\% of the laying hen flocks were infected with Se and St (www.agrimatie.nl). 


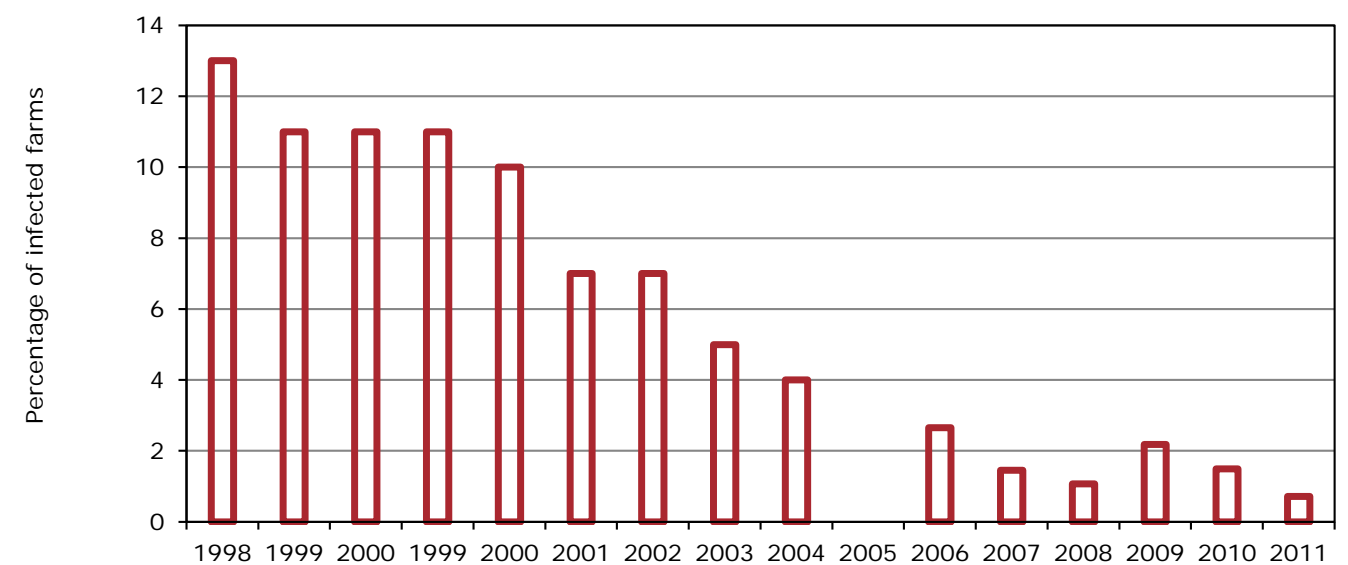

Year

Figure 3.4 Results of policy decisions with respect Se/St eradication programme (www. agrimatie. nl) a) a) No values for 2005 could be found

\subsection{Implementing quality programmes}

\section{Problem}

Food scandals in the 1990s led to a loss of consumer confidence. The existing product control was not sufficient to ensure a good and safe product. As a result there was an increasing demand for more process control to complement product control.

\section{Evaluation based on the framework}

\section{Objectives of the programme}

The objective of the quality programmes was to improve hygiene and guarantee safe food. To safeguard produced food, each link in the production chain has to apply the strictest quality principles. Within the framework of this level of quality assurance, also actors in the chain (for example compound feed companies) must comply with the standards (Figure 3.5).

In addition to this self-regulated approach with requirements exceeding minimum regulatory standards, the EU developed food safety legislation, for example the 'General Food Law' (Regulation $178 / 2002$ ) and hygiene regulations (Regulations 852/2004, 853/2004 and 854/2004). Food companies are liable in the event of food safety incidents (Wever et al., 2010). 


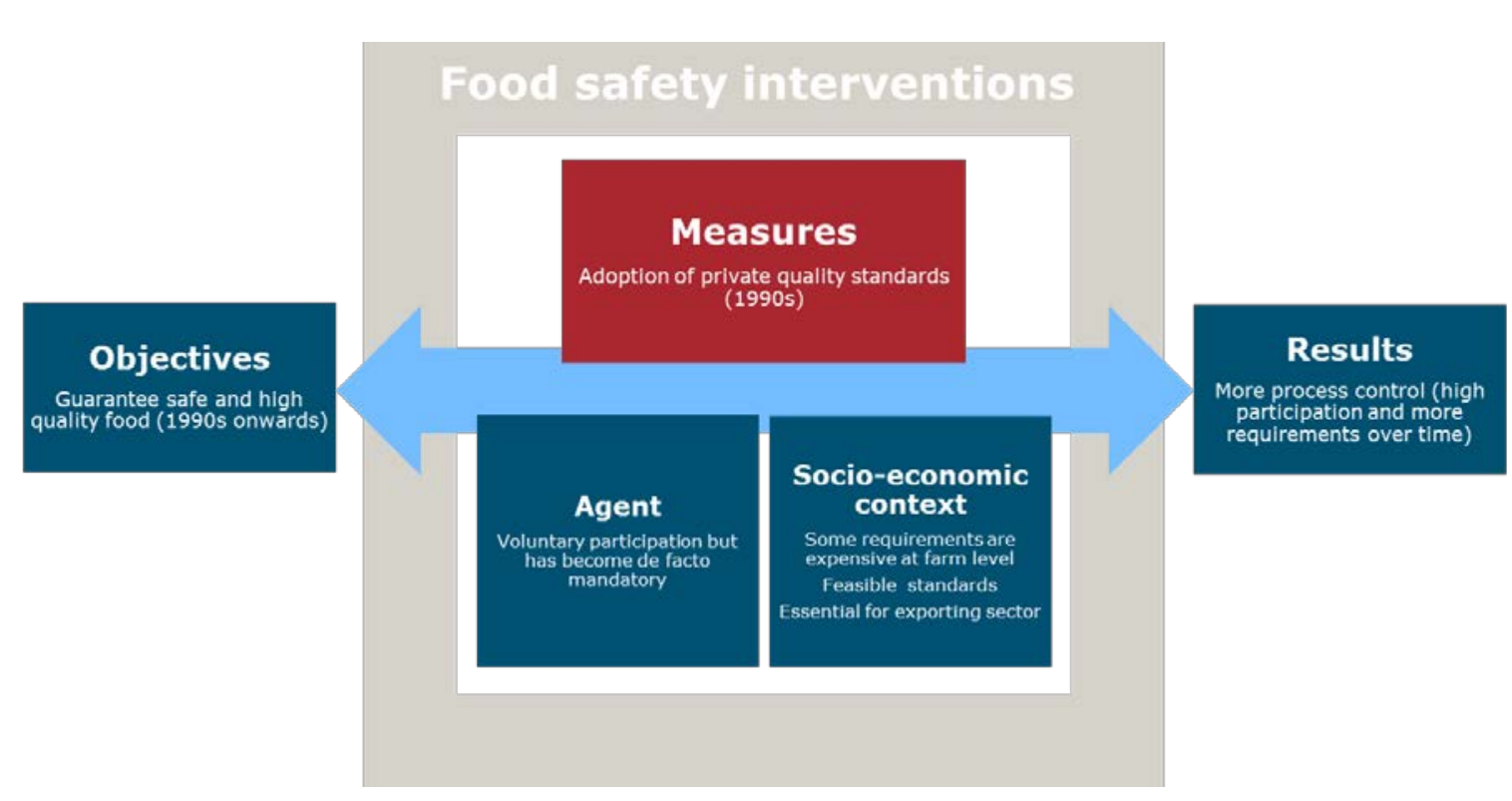

Figure 3.5 Private quality interventions within the evaluation framework.

\begin{abstract}
Measures
Implementing quality assurance programmes based on GMP or HACCP procedures safe and high quality food could be guaranteed. The development of many private quality standards complements public regulations. These regulations are more stringent than the statutory requirements. In the early 1990s the joint livestock sector developed a system for promoting, and above all guaranteeing, the quality of livestock, meat and eggs. The livestock sectors in the Netherlands developed the private 'Integrated Quality Management'-IQC system for quality assurance, primarily aimed at control of primary production (Trienekens and Zuurbier, 2008). In this system, every single link in the production chain - from farmers up to and including retail traders - is monitored to ensure the products' quality. ${ }^{4}$
\end{abstract}

The IQC systems have been evolved over time. Originally the focus was mostly on hygiene, but later the scope broadened by including animal health and environmental issues. Each livestock sector has developed its own specific IQC system. For example, to prevent the risk of veterinary drug residues in (free-range) pork, a 'List of Approved Pig Drugs' has been drawn up. IQC pigs can only be treated with those included on this list. This list is constantly updated. ${ }^{5}$ In the remainder of this high-level case analysis we will focus on the pig sector for which two systems have been established ('IKB Nederland Varkens' and 'IKB Varken').

\title{
Agents
}

\section{- Attitude}

The majority of the farmers were motivated to adopt private quality standards. ${ }^{6}$ In this case farmers are expected to act rationally, i.e. not seeking for the highest compliance level and minimising costs as well (Trienekens and Zuurbier, 2008). In the first years meat-processing companies paid bonuses to IQC-certified farmers. Pig farmers have an option since the additional stringent safeguards in place to ensure food safety differ between the two systems that have been established.

- Subjective norm

Once the industry as a whole has adopted the assurance system, which is the case with the IQCsystems, the systems became de facto mandatory (Trienekens and Zuurbier, 2008).

\footnotetext{
4 http://www.adiveter.com/ftp_public/articulo1812.pdf

5 http://www. adiveter.com/ftp_public/articulo1812.pdf

6 There were some farmers who opposed the system.
} 
- Perceived behavioural control

Most farmers had no difficulties implementing the requirements of the IQC system: it mainly consisted of extra administration and strengthening of basic hygiene measures.

\section{Socio-economic context}

- Cost-effectiveness on farm level Extra costs were incurred by participating farmers themselves. However, there were also farmers who opposed the system, because they expected that the extra costs would not be offset by value added benefits. In case of non-compliance, farmers were confronted with extra audits. Most farmers try to avoid (the costs of) extra audits by complying with the standards. The systems implement stricter measures gradually over time, which is essential to keep the necessary support among participating farmers.

- Practical and technical feasibility

Most farmers had no difficulties implementing the requirements of the IQC system, because it mainly consisted of extra administration and strengthening of basic hygiene measures.

- Relevance at sector level

Initially the quality assurance system contributed to the sector's competitiveness through the effects of improved production efficiency and reduced cost of production. Later on, branding and consumers' views of the production system became more important and international competition started to play a greater role. ${ }^{7}$ Currently the system has become the new industry standard.

- Societal impact

The implementation of the quality assurance systems will probably lead to a reduction of risks for animal and human health.

- Undesirable side effects

An example of a marginal negative side effect is the increased use of plastic building materials, because of better cleaning and disinfection purposes, but which are environmentally unfriendly.

\section{Results}

In the pig sector, the IQC systems cover more than $90 \%$ of the national production. The systems have evolved over time such that more stringent measures needed to be adopted to improve quality standards. Quality standards have contributed to food safety (Escriche et al., 2006). For example, HACCP contributes to reducing levels of food-borne pathogens in food production. An overall figure to depict the impact over time, as in the majority of other cases analysed, is not feasible since this case comprises a multi-dimensional approach of measures and general improvements in food-safety which cannot be easily captured in one single parameter.

\subsection{Veterinary use of antibiotics}

\section{Problem}

Antimicrobial resistance is considered to be a major health threat for people. Experts state that high use of antibiotics is an important risk factor for the occurrence and spread of bacteria resistant to antimicrobial drugs. The risk of antibiotic resistance grows in proportion to the amount and frequency of antibiotic use in food animal production. On many livestock farms in the Netherlands antibiotics use was structurally high until 2009. For many years farmers had the possibility to keep large stockpiles of antibiotics on their farms, and without direct supervision of a veterinarian they could decide about how and how frequently to administer it. Contradictorily, the use of veterinary vaccines was strictly regulated.

In Europe, the European Medicines Agency (EMA) started the project 'European Surveillance of Veterinary Antimicrobial Consumption' (ESVAC) in 2010, following a request from the European Commission for the Agency to develop a harmonised approach for the collection and reporting of data on the use of antimicrobial agents in animals from the EU Member States. EC Directive 2001/82/EC

7 http://www.adiveter.com/ftp_public/articulo1812.pdf 
and Regulation 726/2004 formed a legal basis for national authorities to request the pharmaceutical industry to provide data on sales of antimicrobial agents. However, EU member states are to date not yet obliged to provide data about the use of veterinary antibiotics to the EC.

\title{
Evaluation based on the framework
}

\section{Objectives of the programme}

Already before 2000, the Dutch government was engaged to reduce the use of antibiotics in livestock farming. Because of concerns about the use of fluoroquinolones in poultry and veal calf production, already in 1990 the authorities requested the veterinary association to develop an antibiotic policy. The current policy objective is to have a sustainable livestock farming sector, where systematic and abundant use of antibiotics is unnecessary (letter from Ministry of Economic Affairs to Parliament, 25 November 2011). In December 2008, the Dutch Ministry of Agriculture agreed to the Memoranda of Understanding (MoU) 'Antibiotic resistance in livestock' as put forward by the major livestock sectors and the Dutch Veterinary Association (KNMvD). The objective of these MoUs was to realise responsible use of antibiotics and, as a consequence, a reduction of antimicrobial resistance. The policy on reduction and responsible use of antibiotics in livestock was set up as a public-private partnership, with stakeholders from the major livestock production sectors and the Royal Netherlands Veterinary Association taking responsibility for effective measures, supervised and facilitated herein by the national government.

In autumn 2009, the government formulated the following clear policy objectives for veterinary use of antibiotics: $-20 \%$ in 2011 and $-50 \%$ in 2013 and $-70 \%$ in 2015 for livestock production as a whole, in relation to the use in 2009. Since 2011 transparency and benchmarking of antibiotics use per herd and per veterinarian were realised.

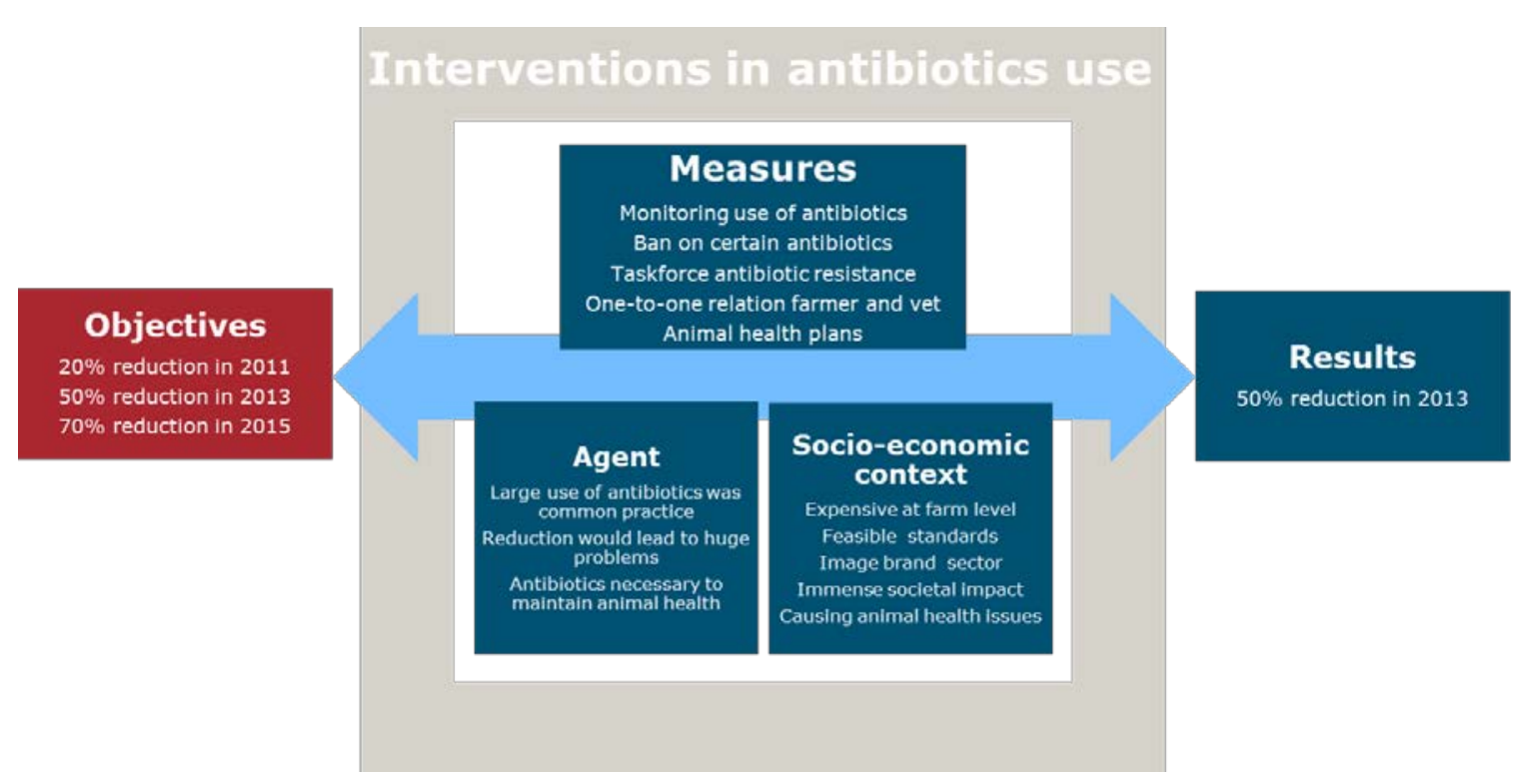

Figure 3.6 Interventions in veterinary use of antibiotics within the evaluation framework.

\begin{abstract}
Measures
The emphasis of the government was on self-regulation and - since 2011 - independent control on antibiotic use by the Netherlands Veterinary Medicines Authority.

Monitoring of the veterinary uses was an important measure introduced. As from 2000, monitoring of antibiotic use focused on the annual total sales and the use of antibiotics in selected panels of farms representing the most important livestock sectors, executed by FIDIN (total sales) and LEI Wageningen UR (sample survey; www. maran.wur.nl). Every year reports were published with detailed information on veterinary antibiotics sales and use. In most sectors the veterinary use of antibiotics
\end{abstract}


increased every year, which led to intensive media attention and increasing pressure from NGOs and politicians.

The MoUs of the livestock sectors stated that several actions would be taken:

a. Establishing a steering committee Antibiotic Resistance in Livestock to implement the action plans to reduce antibiotic use through working groups per sector with farmers, veterinarians etc.

b. One contracted veterinarian per herd

c. Mandatory periodical veterinary herd inspections

d. Introduction of so-called 'animal health plans' as a key and mandatory instrument to ensure that livestock farmers will take preventive animal health measures, thus reducing the need to administer antibiotics. Finally, the government announced to enforce restrictions on the use of certain antibiotics of critical importance. Within the Food and Consumer Product Safety Authority (NVWA) the staff capacity necessary for enforcement was made available.

At the end of 2010, the Netherlands Veterinary Medicines Authority (SDa) was established. The SDa is an independent institute, which supports the reduction of the use of antibiotics in animal production in the Netherlands, mainly by setting benchmark indicators for the use of antibiotics. The core tasks of the SDa are being executed by an independent panel of experts from the field of human medicine, veterinary medicine and epidemiology. The independent SDa expert panel annually defines benchmark indicators for responsible use of antibiotics, making use of science-based methods. The benchmark indicators serve as guidelines for farmers and veterinarians and are specified per animal species. The SDa expert panel recommends reduction programmes for farms and veterinary practices that are systematically using large quantities of antibiotics. The SDa expert panel monitors the quality of the data on the usage of antibiotics and of the reduction programmes. The SDa expert panel also sets benchmark indicators for antibiotics that are critical to human medicine and defines the conditions for their use.

Veterinarians may prescribe antibiotics only if they have diagnosed an infection that can be treated by these drugs. The diagnosis must be based on a clinical inspection of the livestock. The entire course of antibiotics must then be administered by the veterinarian. Antibiotics may not be stored at the farm. The so-called 'UDD regulation', implemented in 2014, is a law that states that antibiotics can only be administered by a veterinarian. In March 2014 these rules were introduced:

- Farmers who deliver animals for slaughter which contain high levels of antibiotic residues will have to pay a fine.

- Pet stores may not sell antibiotics.

- 'Last-resort' antibiotics for humans may also only be administered to sick livestock as a last resort.

- Raw antibiotic substances may not be stored or sold without a licence ( https: // www. government. nl/topics/antibiotic-resistance/contents/antibiotic-resistance-in-livestockfarming).

Due to the public health risk and by way of precaution, the Netherlands Health Council recommended in the short term to reserve all new antibiotics - as well as existing antibiotics not yet used or no longer used in veterinary medicine - for use on humans. One of the medicines on this list is tigecycline. In addition to tigecycline, this list includes carbapenems, glycopeptides (e.g. vancomycin), daptomycin, oxazolidinones (e.g. linezolid) and mupirocin. Also, the Health Council advised to take measures to ensure the discontinuation of the use in animals of fluoroquinolones, aminoglycosides and beta-lactams in the long term, apart from therapeutic use in individual animals based on good diagnostics and according to professional guidelines. The Committee expected that restricting the use of these antibiotics would enable them to continue to be used on humans. The Committee found a longer period of out-phasing necessary so as not to endanger the treatment of animal infections. It did, however, recommend that these measures were implemented as soon as possible.

The Committee expressly stated that it felt a general ban should be applicable if the professional guidelines were not closely followed in daily practice. The Committee made recommendations that were intended to result in a reduction in the use of antibiotics in general and some classes of antibiotics in particular. 
Antibiotic resistance is an international problem; some of the Committee's recommendations would therefore have more effect if they were to be adopted in an international context. However, the Committee believed that even if measures would only be taken in the Netherlands, this could certainly also lead to a reduction of the problem.

\section{Agents}

Over time a gradual change evolved in how the livestock farmers approached the problem.

\section{- Attitude}

Livestock farmers are doing their utmost to keep their animals healthy. Not only to improve production but also to maintain adequate levels of animal welfare. Metaphylactic and prophylactic use of antibiotics were common practice and a rather successful tool to achieve these goals. It seems that many farmers personally chose to change the routine use of antibiotics, maybe because they were worried about the health impact on themselves, their families and employees. Decisions of farmers are driven by more than only money (for example the emerging of MRSA).

- Subjective norm At the start in 2007/2008, the subjective norm was that banning, or strongly reducing antibiotic usage, would lead to uncontrollable disease outbreaks, and impoverished animal welfare. This view was commonly shared amongst livestock farmers as well as amongst significant influencers (veterinarians, feed industry). A few years later the subjective norm changed, probably partly as a result of the increasing sense of urgency and the clear policy objectives.

- Perceived behavioural control

Livestock farmers thought that without having access to antibiotics they were not able to maintain their livestock healthy. At first, veterinarians and farmers expected a high impact from the reduction of antibiotics use on production results, such as mortality, growth rates and feed conversion. However, early experiences revealed that antibiotic use could be reduced substantially without compromising production.

After this initial phase of resistance towards the compulsory reduction target a shift in especially subjective norm and attitude occurred. Successful examples of farmers drastically reducing antibiotic usage were shared among farmers. Also positive support from veterinarians led to the substantial reduction in recent years.

\section{Socio-economic context}

- Cost-effectiveness on farm level On many farms improvement was possible by implementing a series of relatively simple and inexpensive management changes, e.g. more frequent checking of climate conditions and monitoring of the behaviour of the animals, improving drinking water quality, improving hygiene measures.

- Practical and technical feasibility

They key success factors to reduce antibiotic use are:

a. to monitor the level of antibiotic use on the farm

b. to strengthen the preventive animal health management.

A feasible large-scale monitoring programme evolved over time, first as a sample, while in a later phase all livestock farms were included. Strengthening management also evolved over time.

- Relevance at sector level

Up to 2008 the antibiotic use was structurally high on many livestock farms in the Netherlands. Most probably, at that time only a minority of veterinarians and farmers were focused to minimise the use of antibiotics, so there was much room for improvement.

- Societal impact

Antimicrobial resistance is considered to be a major health threat for people, partly caused by transmission of resistant micro-organisms from livestock. Experts state that high veterinary use of antibiotics is an important risk factor, but level of attribution is yet unknown. As a consequence, it is expected that a reduction of antibiotic use in livestock will contribute significantly to decreasing the health risks for humans. Only in recent years, there is a growing persuasion that pet animals, as well as 'medical tourists' and the environment, are important risk factors for the spread of antimicrobial resistance in humans. 


\section{- Undesirable side effects}

If a reduction of antibiotic use would have led to animal health problems, then this would have been a very negative side effect, both for farm economics and animal welfare. But there are indications that reduction was feasible on many farms since total use decreased by more than $50 \%$ in the years 2009-2013, without such negative effects. However, it seems likely that a further reduction of antibiotics use will put more stress on the health and welfare of the animals, and the income of the farmers.

\section{Results}

The policy on antibiotic use in livestock has been successful. In 2012 the objective of a $50 \%$ reduction of total sales, as compared to 2009, had already been realised (see Figure 3.7). By 2014 the sales of veterinary antibiotics had dropped by more than 58\%, from 495 tonnes of active substance in 2009 to 207 tonnes in 2014. Moreover, since 2013 almost no critically important antibiotics have been used in the major livestock sectors. The reduction in use of antibiotics has resulted in lower levels of antibiotic resistance in most animal species. The first substantial decrease of the total sales was realised in $2008 / 2009$ (approximately $10 \%$ ), which is very shortly after the first presentation of concrete policy objectives. It seems that farmers were already seriously influenced by the increasing negative attention from society, in the years 2000-2007, both for the problem of MRSA/ESBL and for the large use of antibiotics. Farmers and their families appeared to be heavily infected with MRSA and hospitals refused to immediately treat them, not even in the urgent case of a serious disease. This certainly has contributed to the awareness of the human health problems. This situation seems to have created a sense of urgency among Dutch farmers. Several farmers took action and sometimes to their own surprise they found out that substantial reductions of antibiotic use were possible, without harming their technical and economical results. Furthermore, the concrete threat that veterinarians may lose their pharmacy licence has probably led to intensive actions from their side to support the efforts to reduce the use of antibiotics. However, also in the years from 2009 up until now, the reduction of antibiotic use is still partly voluntary. Non-prudent use of antibiotics in recent years has been tackled seriously. Individual farms that had a valid reason to use antibiotics and unfortunately have not succeeded in reducing their usage have not yet had sanctions imposed.

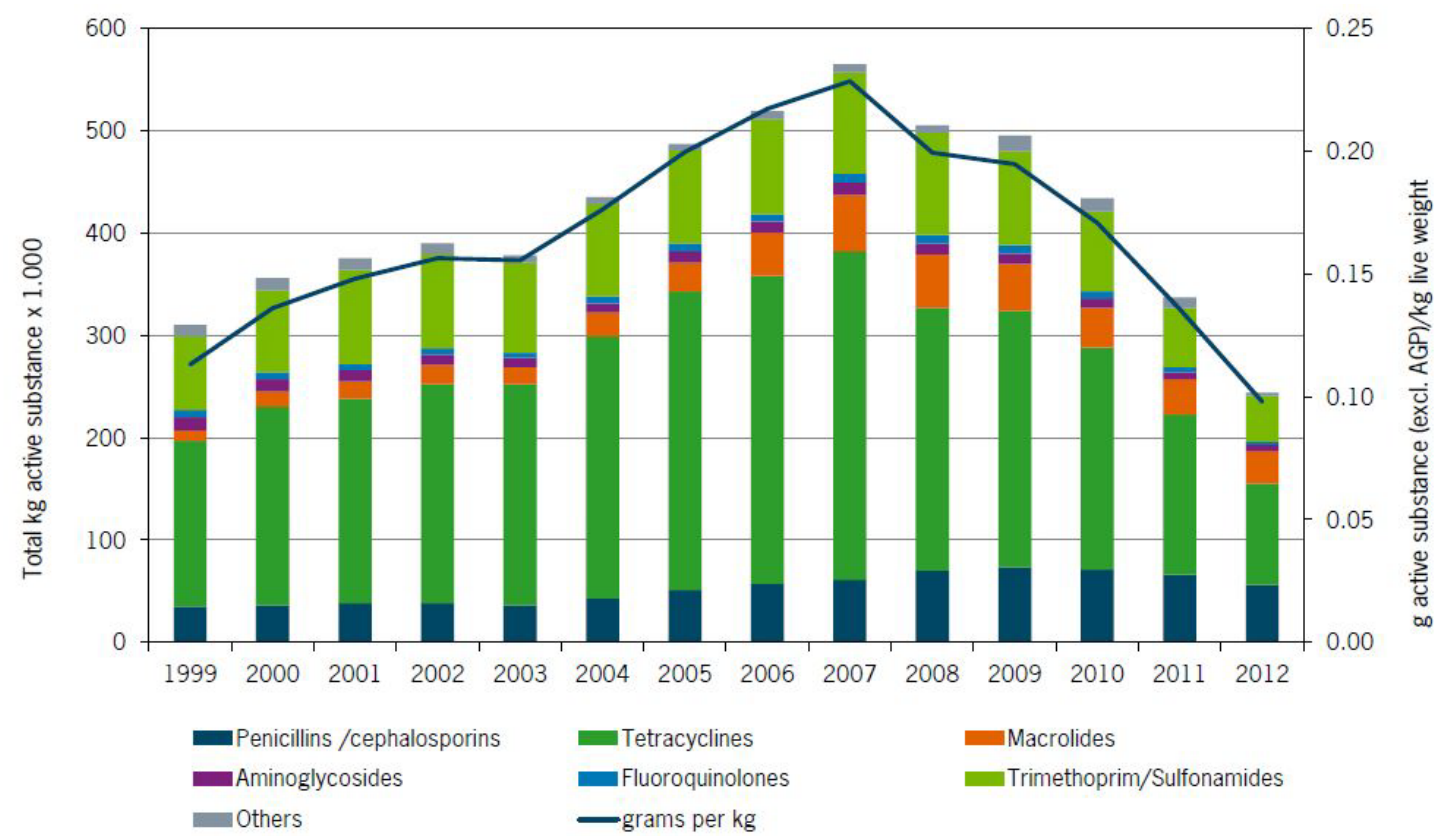

Figure 3.7 Results of policy decisions with respect to veterinary use of antibiotics (Netherlands Veterinary Medicines Authority (SDa)). 


\subsection{Animal welfare}

\section{Problem}

Animal welfare is an important concern for many citizens in the Netherlands. Citizens have increasingly become aware of several negative side effects of conventional livestock farming (Ingenbleek et al., 2012). Bracke et al. (1999) define animal welfare as the quality of life as perceived by the animal itself ${ }^{8}$. An animal is in a good state of welfare if it can adapt to its circumstances and achieves a state which it experiences as positive (www.uu. nl).

\section{Evaluation based on the framework}

\section{Objectives of the programme}

The general policy objective is to increase animal welfare by improving the circumstances in the animal production chain (Figure 3.8), since animals are sentient beings, by paying full regard to the welfare requirements of animals (Lisbon Treaty, article 13). An important factor is the assessment of the utility and necessity of the use of animals, for example in the case of for production or animals in a circus.

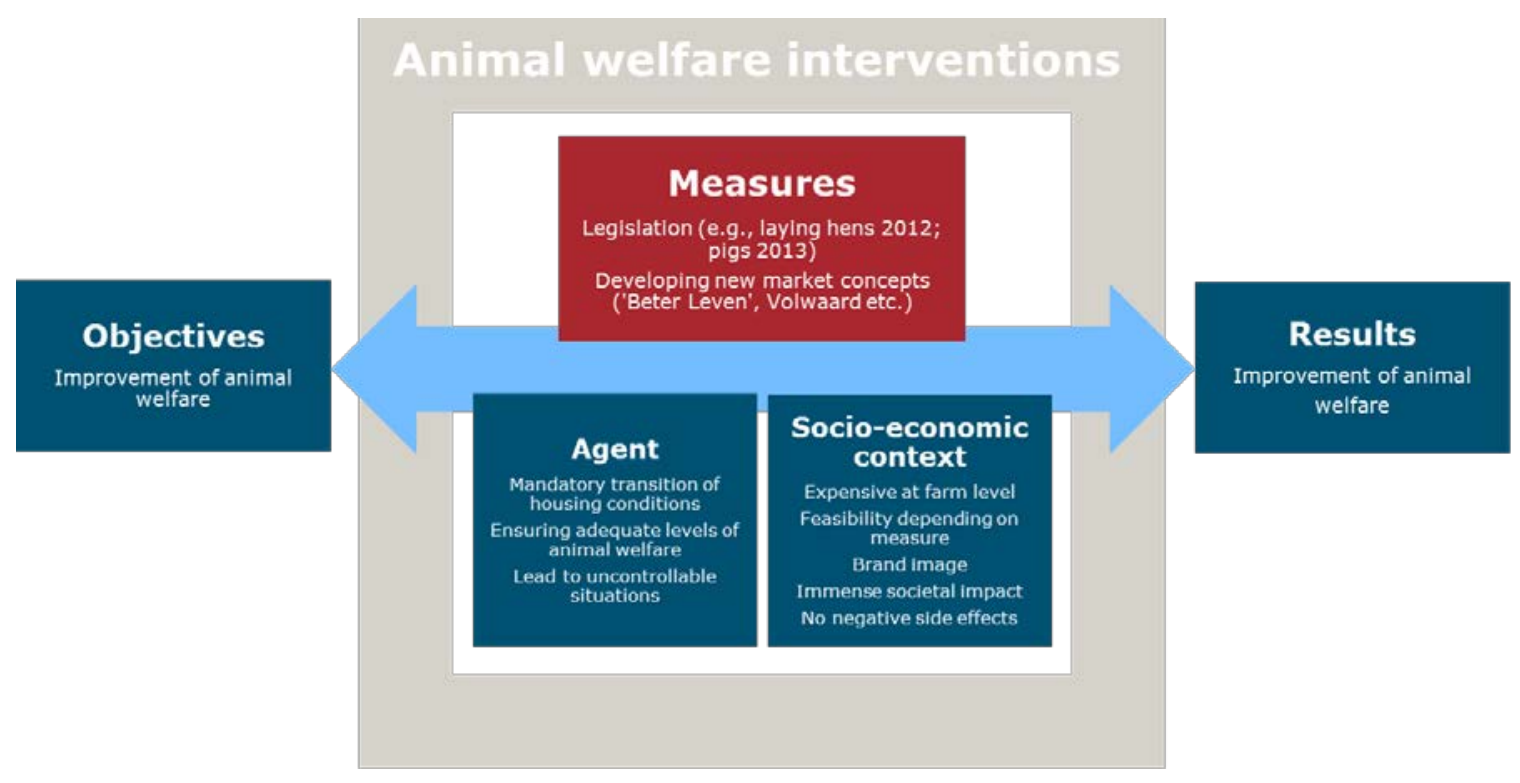

Figure 3.8 Animal welfare interventions within the evaluation framework.

\section{Measures}

Policy-makers responded to the animal welfare concerns by developing policy instruments that would aid in improving animal welfare assurance schemes (European Commission, 2007; FAO, 2008; FAWC, 2009). ${ }^{9}$ Moreover, the private market came with several new concepts and market segments with improved animal welfare housing systems.

The animal welfare policy approach in the Netherlands shows similarities with the antibiotic use policy. Again, there has been major attention from NGOs, media and politicians, and the primary focus of the government is on self-regulation. However, also on top of the EU minimum legal levels, more stringent national regulation was established. The Animal Health and Welfare Act of 1993 was followed by several general administrative orders (abbreviated to AMvBs in Dutch). In 2013 the Animal Act came

\footnotetext{
8 Bracke, M.B.M, B.M. Spruijt, J.H.M. Metz (1999) Overall welfare reviewed.

Part 3: Welfare assessment based on needs and supported by expert opinion. Netherlands J ournal of Agricultural Science 47: 307-322.

9 References from: Ingenbleek et al. (2012).
} 
into force. This Act is more objective oriented and less prescriptive than previous legislation. The problem with this approach is that it is very difficult to measure the realised level of animal welfare.

\section{Agents}

- Attitude

Initially, farmers disagreed with statements that animal welfare was compromised on livestock farms. Later some farmers became interested due to the observed negative impacts on production of impaired animal welfare. Minimum animal-friendly housing conditions were made mandatory and become more stringent over time. In addition, on a voluntary basis, motivated farmers have taken additional measures to improve animal welfare. In many cases the primary motivation arose from interesting opportunities in the market.

- Subjective norm

Twenty to thirty years ago the predominant view on animal welfare was that optimal production was only possible when an adequate level of animal welfare was ensured. 'If animal welfare should be seriously impaired such high production levels would not be possible.' This has changed over time and an increasing number of farmers are aware of the welfare needs of their animals.

- Perceived behavioural control

In the early phase of transition to improve housing conditions, i.e., more space or group housing of sows to express the animals normal behaviour, farmers were anxious that it would lead to uncontrollable situations (e.g. animals fighting, mutilation and reduced production). More recently, a similar concern applies to the possible ban on tail docking in piglets. Preventive animal health management can be a serious challenge for many livestock farmers.

\section{Socio-economic context}

- Cost-effectiveness on farm level Only part of the extra costs of realising better conditions for animal welfare could be compensated by improved animal health and better technical results. By setting relatively high animal welfare standards, the EU adds costs which are not required to be incurred by producers in non-EUcountries, and this will harm the competitiveness of EU producers. This situation could be avoided by creating market niches in which consumers pay extra for food from animal-friendly production systems.

- Practical and technical feasibility

The feasibility of animal welfare measures differs largely. For example, banning tail docking in piglets requires very specific management qualities of the pig farmer, to avoid cannibalism. If the farmer succeeds, the extra costs of this measure can be negligible. On the other hand, increasing the amount of living space for pigs is easy when building a new pig house (but the extra costs are substantial).

- Relevance at sector level

Animal welfare improvements will improve brand image of livestock farming. By setting relatively high animal welfare standards, the EU adds costs which are not required to be incurred by producers in non-EU-countries, and this will harm the competitiveness of EU producers. This situation could be avoided by creating market niches in which consumers pay extra for food from animal-friendly production systems.

- Societal impact Animal welfare improvements are a main concern to NGOs and politicians, and to a lesser extent also to the general public. An increasing part of the Dutch population believes that animals are entitled to the possession of their own lives and that their most basic interests-such as the need to avoid suffering should be afforded consideration.

- Undesirable side effects Improving animal welfare will probably lead to reduced production efficiency, which results in higher emissions of manure and greenhouse gasses from livestock. The requirement to invest in new technologies has probably contributed to a shake-out of small family farms. Twenty years ago in the Netherlands substantial progress was made through public financing of research experiments, for example to develop alternative housing systems for laying hens. 


\section{Results}

In the past decade some livestock producers were relatively proactive in developing market concepts. Several new concepts have been developed, in close cooperation with the NGO Dutch Protection of Animals, researchers from Wageningen UR and others. A few examples: a system of stars for Improved Life ('Beter Leven') for several egg and meat products, e.g., Comfort Class-pigs. Hopster (2010) noticed clear progress in animal welfare in the Netherlands. Since 2004 calves are kept in groups, and no longer in individual boxes. Moreover, the calves receive some roughage as an integral part of their diet. Houses for dairy cows have significantly improved since the 70s. More attention is spent on good ventilation, sleep comfort and quality flooring. Sows are kept in groups as from 2013. The classical swine fever crisis of 1997 was a defining moment in the public's opinion of intensive livestock farming. After this, the living space for piglets and pigs increased in steps since, pig farmers are also required to provide enough distraction material for their animals, finally, on the way to completely eliminating of castration male piglets, castration has to be performed using proper anaesthesia.

One overarching figure to depict the impact over time on animal welfare cannot be easily quantified, as in the majority of other cases analysed, since this case comprises multiple interventions in several livestock species and no single construct to measure animal welfare is available. Hopster (2010) also concludes that not only legislation, but above all the confluence of circumstances and shared commitment of stakeholders determine the actual room for improvement of animal welfare.

\subsection{Ammonia emissions}

\section{Problem}

Intensive livestock production cause airborne emissions (e.g., ammonia, odour, non- $\mathrm{CO}_{2}$ greenhouse gasses and particulate matter) which results in risks for the environment, biodiversity and human health. Ammonia as an environmental threat became evident in 1982, when high levels of ammonium sulphate were found in rain water (Starmans and Van der Hoek, 2007). The first articles on the acidification effects of ammonia were published in the 80s. Emission standards have become increasingly stringent in European member states and the livestock industry was challenged to comply with these standards (Melse et al., 2009).

\section{Evaluation based on the framework}

\section{Objectives of the programme}

Regarding ammonia emissions, the objective of the Dutch government is to minimise the emissions from the livestock industry to protect the environment and human health. E.g., National Emission Ceiling for ammonia (NEC Directive) of 128 kilotonnes in 2010 (Figure 3.9). 


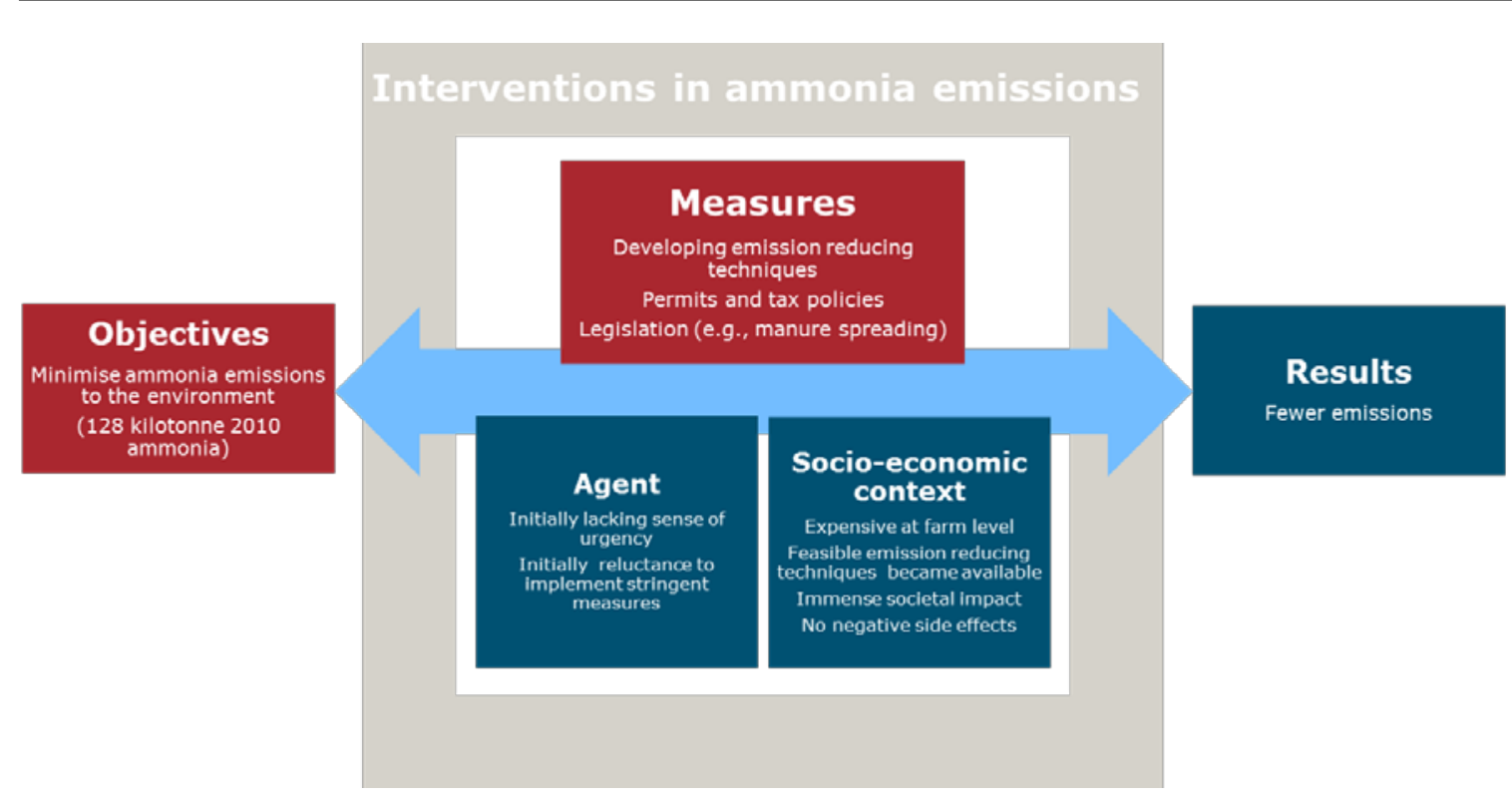

Figure 3.9 Interventions in ammonia emissions within the evaluation framework.

\section{Measures}

The Netherlands were front runners in the ammonia emission dossier; most other EU Member States followed in the 1990s. Integrated Pollution Control (IPC) has been adopted by the European Union and been put in force as Integrated Pollution Prevention and Control (IPPC) by ratification of the EU Directive 96/61/EC (EC, 1996).

In the Netherlands during the last 30 years considerable efforts have been put into the development of ammonia emission reducing techniques in livestock farming. The regulatory process started in 1987 with an obligation to cover outside liquid manure storages (Public Nuisance Act) and to apply manure with low emission techniques (Use of Animal Manure Decree). The Dutch Ammonia and Livestock Farming Act came into force in 2002.

Livestock farms need an operating permit that takes into account the whole environmental performance, covering e.g., emissions to air, water and land, generation of waste and energy efficiency.

\section{Agents}

- Attitude

Initially amongst farmers and politicians the sense of urgency was lacking and agents were reluctant to implement stringent measures on a voluntary basis. In the 1990s many farmers believed that ammonia emission was not a very serious problem and measures would primarily cost too much without any benefit. In later years the understanding of the relevance of the impact on image and the importance of sustainable production systems increased.

- Subjective norm Many farmers and also politicians thought that reduction of ammonia emissions should not be a priority, because the problems for the environment were quite limited. Moreover, ammonia is invisible and there are no severe implications for public health. Nuisance caused by odorous gases from livestock houses and manure received more serious attention, already in the 1970s, caused by intensification of animal production on one hand and the strong urbanisation on the other hand (Tamminga, 1992).

- Perceived behavioural control

The low-emission manure spreading techniques were perceived by farmers as relatively easy to implement. However, low-emission housing was much more 'difficult' to implement, mainly because of the high investment costs. 


\section{Socio-economic context}

- Cost-effectiveness on farm level

The regulations caused significant extra costs and were borne by farmers themselves. Fiscal arrangements stimulated the early adoption of above legal measures.

- Practical and technical feasibility

New technologies were enabled for the reduction of ammonia emissions to the environment, which were relatively simple to implement.

- Relevance at sector level

In the near future especially dairy farmers will have to implement measures as well, as a result of the National Emission Ceilings (NEC) and Natura 2000.

- Societal impact

Airborne emissions caused by intensive livestock production are a risk for the environment and biodiversity. Furthermore, reduction of ammonia emissions also contributes to odour reduction.

- Undesirable side effects

The requirement to invest in expensive new technologies has probably contributed to a shake-out of small family farms. Inappropriate use of ventilation measures (e.g., air washers) to reduce environmental impact may lead to animal health and welfare issues, caused by a worsened barn climate.

\section{Results}

Several effective emission-reducing feed management strategies and a large variety of low-emission livestock housing systems were developed and applied in livestock farming (Melse et al., 2009). The ammonia emissions in the Netherlands are still declining over time ( $\mathrm{Jimmink}$ et al., 2014). This decrease was due to emission reductions from agricultural sources (Figure 3.10). The direct emissions from animal husbandry decreased slightly because of decreasing animal population and measures to reduce emissions from animal houses. Application emissions decreased because of measures taken to reduce the emissions from applying manure to soil and to reduce the total amount of $\mathrm{N}$ applied to soil. At present, $90 \%$ of Dutch $\mathrm{NH}_{3}$ emissions come from agricultural sources. As a result of ammonia reduction measures the ammonia deposition decreased by $30 \%$ to $40 \%$, odour reduced and animal manure is used for crop growth more efficiently, hence reducing the use of fertilisers (source: Letter to Parliament about ammonia emission and deposition 21-10-2014).

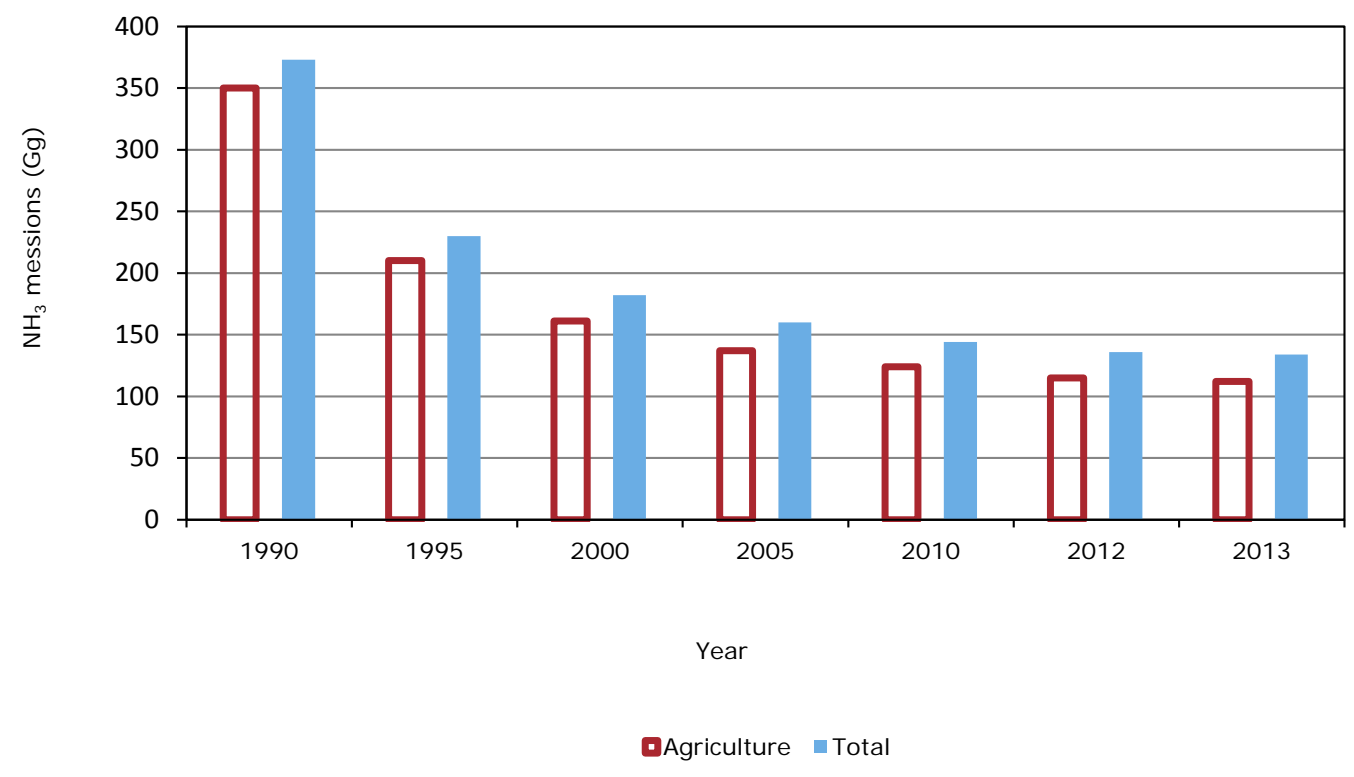

Figure 3.10 Results of policy decisions with respect to ammonia emissions (www.rivm. nl). 


\subsection{Lessons learned from previous intervention programmes}

A meta-analysis of the six policy interventions is presented in Table 3.1. These interventions were either objective-driven or measure-driven or a hybrid. The veterinary antibiotic policy was primarily objective-driven, whereas most other analysed policies were measure-driven, or were more or less intermediate policies (i.e., ammonia emissions). Moreover, the policy objectives were met over time, independent of the context (i.e., agent and socio-economic aspects). This was mostly an iterative process, sometimes lasting several decades, where in general measures implemented became mandatory if objectives were not met and effective measures became available.

Other factors or circumstances that influence the choice of an objective-driven or measure-driven approach are:

\section{- Sense of urgency}

A situation in which policy makers feel a strong sense of urgency can be an important reason to choose a (mandatory) measure-driven approach, such as during the Q-fever crisis. Swift action had become inevitable and stringent measures were enforced.

- Availability of effective measures

A measure-driven approach is much more likely if a proven set of effective measures is available.

In the case of veterinary use of antibiotics, there was a clear policy objective, at least since 2009, but because no clear measures were instantly available in the beginning, veterinarians and farmers were quite confused and unwilling or unable to take action. However, as soon as successful individual results were realised and a substantial use reduction on sector level was measured, the opinions changed rapidly.

Furthermore, for an objective-driven approach it is also important that results can be objectively measured and the individual agents can be held accountable (via regulation).

\section{Table 3.1}

Criteria for assessment evaluation framework per case. ${ }^{1}$

\begin{tabular}{|c|c|c|c|c|c|c|}
\hline & Q fever & $\begin{array}{l}\text { Salmonella } \\
\text { Se/ St }\end{array}$ & $\begin{array}{l}\text { Quality } \\
\text { programme }\end{array}$ & $\begin{array}{l}\text { Veterinary } \\
\text { use of } \\
\text { antibiotics }\end{array}$ & $\begin{array}{l}\text { Animal } \\
\text { welfare }\end{array}$ & $\begin{array}{l}\text { Ammonia } \\
\text { emissions }\end{array}$ \\
\hline Sense of urgency policy makers & Very high & Low & Low & High & Low & Medium \\
\hline Availability of effective measures & Yes & Yes & Yes & No & Yes & Yes \\
\hline $\begin{array}{l}\text { Agent } \\
\text { - Attitude } \\
\text { - Subjective norm } \\
\text { - Perceived behavioural control }\end{array}$ & $\bullet \bullet$ & $\bullet \bullet$ & $\bullet \bullet$ & $\bullet$ & $\bullet$ & $\bullet \bullet$ \\
\hline $\begin{array}{l}\text { Socio-economic context } \\
\text { - Cost-effectiveness on farm level } \\
\text { - Practical feasibility } \\
\text { - Relevance at sector level } \\
\text { - Societal impact } \\
\text { - Undesirable side effects }\end{array}$ & $\bullet \bullet \bullet$ & $\bullet \bullet$ & $\bullet \bullet$ & $\bullet \bullet \bullet$ & $\bullet \bullet$ & $\bullet \bullet \bullet$ \\
\hline Result & $\bullet \bullet \bullet$ & $\bullet \bullet \bullet$ & $\bullet \bullet \bullet$ & $\bullet \bullet \bullet$ & $\bullet \bullet$ & $\bullet \bullet \bullet$ \\
\hline
\end{tabular}

The historical cases reveal that the process of how policy instruments evolve over time depends on the context. In general, during the last decades governmental authority has become less accepted, and spontaneous compliance to legislation has reduced, due to cultural developments like individualisation. 
Furthermore, traditional policies have become increasingly inefficient because the issues that need regulating have become increasingly complex and policy implementation and enforcement become more costly (Bunte et al., 2004). Therefore, it is likely that objective-driven policies, without the need of extensive and costly enforcement activities, will become more and more preferred.

\subsection{Revised framework}

The general approach of the evaluation framework (Figure 2.1) is focusing on the realisation of objectives and the implementation of measures by the agents. In this general approach the dynamic element of evaluating the current policy and choosing a preferred policy approach is missing. This element should be included in a revised dynamic version of the evaluation framework. The revised framework, or 'policy decision tree', may guide decision-makers in forming future policies by setting policy priorities. Two key decisions form the core of the dynamic policy decision tree:

1. Are the results in line with the policy objectives?

2. What is the preferred revised policy approach: objective- and/or measure-driven?

The before-mentioned key elements of formulating an effective policy strategy are summarised in Figure 3.11. Both key decisions require information to make a well-informed decision. Obviously, in case of knowledge gaps decision making is hampered.

\section{Are the results in line with policy objectives?}

If envisaged results are not achieved then there is an obvious need to revise the current intervention strategy. However, if this objective is not further specified in target levels there remains room for interpretation whether or not the objectives are met. In general, it is recommended to set clear common objectives, because it is an important condition for successful change.

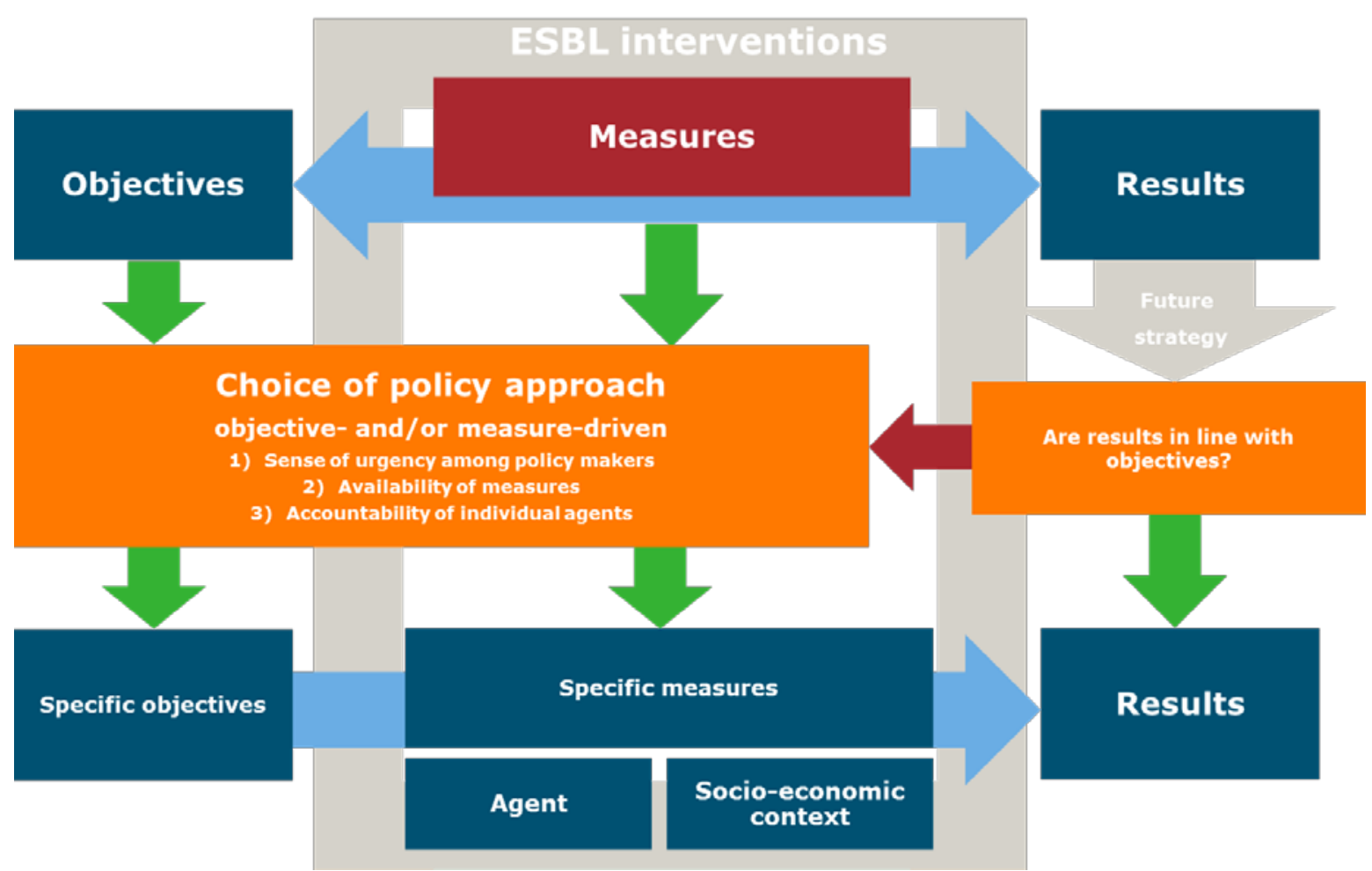

Figure 3.11 Revised evaluation framework. 


\section{Choice of preferred policy approach}

If specific policy actions are needed, first a choice should be made between an objective-driven or measure-driven approach. A dual pathway can also be considered whereby policies with respect to objectives and measures are both revised simultaneously.

A measure-driven approach may be preferable if:

- There is a crisis (strong sense of urgency among policy makers; immediate action is needed);

- A proven set of clear, effective and practical measures is available;

- Compliance of implementation can be enforced and measured;

- Results are difficult to measure (accountability per individual stakeholder).

An objective-driven approach may be better if:

- There is time to create a sense of urgency among stakeholders;

- Multiple measures may be effective;

- The performance of stakeholders largely varies;

- The effectiveness of measures depends on the individual circumstances;

- Results can be measured adequately (accountability, preferably per individual stakeholder). 


\section{$4 \quad$ Policy decisions for ESBL}

Currently, the policy on ESBL is evolving. The key characteristics in terms of its current and future objectives, measures implemented, agent characteristics, socio-economic context and achieved result are analysed and described in this chapter.

\subsection{Past and presence policy decisions ESBL}

In this paragraph the current ESBL policy is described, based on the original evaluation framework as formulated in Chapter 2.

\subsubsection{Objectives}

Following the general framework approach, the first step to control ESBL is to define clear objectives, preferably supported by all relevant stakeholders. The current policy objective is general in nature since the stated goal is to reduce ESBLs (Figure 4.1). The rational to reduce ESBLs is that patients who are infected with resistant bacteria have more limited options for treatment.

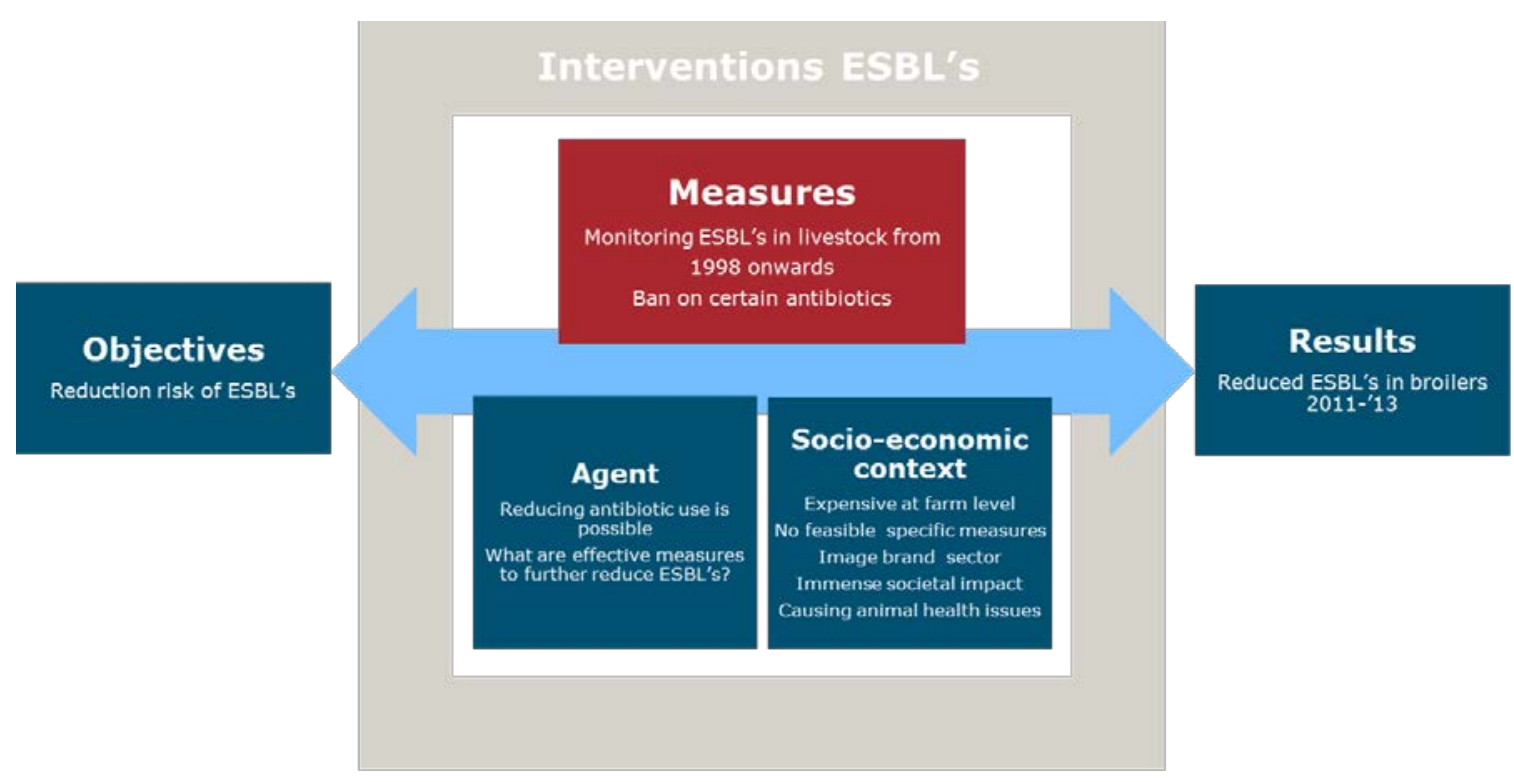

Figure 4.1 Current policy decisions with respect to ESBL control within the evaluation framework.

\subsubsection{Measures}

The current controlling framework for ESBL enables stakeholders to choose measures that stakeholders can implement themselves. Moreover, objectives and measures to reduce antibiotic use have a positive effect on ESBL as well (e.g., monitoring antibiotic sales, taskforce antibiotic resistance, 1-to-1 relation between farmer and veterinarian, animal health plans). However, some concrete measures are adopted as well, which entail monitoring ESBLs and banning specific antibiotics.

\section{Monitoring of ESBLs}

Monitoring is one of the main currently adopted measures. Surveillance of resistance to extended spectrum cephalosporins in the Netherlands is based on non-selective culturing of indicator isolates (E. coli and Enterococcus spp) and zoonotic bacteria (Campylobacter spp and Salmonella spp) derived 
from faeces or meat. Monitoring of food producing animals is routinely done as prescribed by EFSA guidelines. ${ }^{10}$ Per epidemiological unit or meat product one isolate of bacterial species is cultured and its susceptibility to a panel of antibiotics is determined. Monitoring started in the Netherlands in 1998 (Maran, 2015; Dierikx, 2014).

\section{Ban on specific antibiotics}

According to a Committee of the Health Council ${ }^{11}$, there are three groups of resistant bacteria that pose the largest threat to public health and for which there are concerns about a possible causal relationship with the use of antibiotics in food animal production: vancomycin-resistant enterococci (VRE), methicillin-resistant Staphylococcus aureus (MRSA) and the bacteria that produce extended spectrum beta-lactamase (ESBL). The Committee stated that the greatest microbial risk to public health arising from food animal production at the present and in the near future is probably posed by ESBL-producing bacteria. The fact is that scientific evidence reveals that the use of these antibiotics has promoted the occurrence of ESBL-producing bacteria. The Committee recommended that the antibiotics used as a last resort to treat infections caused by ESBL-producing bacteria should be reserved for this treatment. For this reason, the Committee proposes barring tigecycline from the veterinary market and discouraging the veterinary use of carbapenem class antibiotics by making the 'cascade system' more stringent. The emergence of resistance to carbapenems is a major issue since carbapenems are considered as last-resort antibiotics often used to treat infections with a multi-drug resistant organisms (e.g. ESBL) (Dierikx et al., 2014).

The Committee of the Health Council advised to ensure that resistance is actually reduced, the preventive and systematic use of all beta-lactam antibiotics in food animal production should be stopped in the longer term. In the Netherlands, cephalosporins are not or no longer used in foodproducing animals. In exceptional cases, beta-lactam antibiotics will need to remain available for therapeutic use in individual animals with good diagnostics.

\subsubsection{Agents}

- Attitude

The attitude of livestock farmers towards ESBLs is similar to their attitude towards veterinary antibiotic use, mainly because of the assumed strong relationship between antibiotic use and the development of antimicrobial resistance. The awareness of the risks of resistance and antibiotic use has increased because some farmers have personally experienced an infection's adverse impact (especially with MRSA), as they themselves, their relatives or personnel were isolated or had difficulties to access hospital treatments. This seems to have worried many other farmers.

- Subjective norm It seems that many farmers personally chose to change the routine use of antibiotics, maybe because they were worried about the health impact of antibiotic resistance on themselves, their families and their personnel.

- Perceived behavioural control Livestock farmers do not expect to be able to take the intended measures since it is unclear which means and skills are needed. Moreover, measures at farm level become only relevant if purchased animals are ESBL free.

\subsubsection{Socio-economic context}

- Cost-effectiveness on farm level Since 2009 many veterinarians and farmers experienced that substantial reductions of antibiotic use were possible without compromising farm production. Currently, it is still not clear which extra measures will be effective to further reduce the prevalence of ESBLs. The lack of scientific

\footnotetext{
${ }^{10}$ Report from the Task Force on Zoonoses Data Collection including guidance for harmonised monitoring and reporting of antimicrobial resistance in commensal Escherichia coli and Enterococcus spp. from food animals. http: // www. efsa. europa.eu/en/efsajournal/pub/141r.htm.

${ }^{11}$ Health Council of the Netherlands' report: https://www.gezondheidsraad. nl/sites/default/files/201116. pdf.
} 
information complicates evaluating the epidemiological effectiveness of possible measures and the associated costs.

- Practical and technical feasibility

Reducing antibiotic use has been made possible by relatively simple management changes. Other ways to reduce the prevalence of ESBLs in the future will probably be linked to strengthening the preventive animal health management and the biosecurity of the farm. The practical feasibility depends on the concrete measures that will be most effective to reduce ESBLs.

- Relevance at sector level

The strong decrease of veterinary antibiotic use and the banning of specific antibiotics that are of critically importance for human health care have already partially reduced ESBLs in livestock. A long-term continuation of the current relatively low level of antibiotic use may eventually lead to further reducing ESBLs, maybe at a slower pace but much is yet unknown.

- Societal impact

Antimicrobial resistance is considered to be a major health threat for people. Resistance is partly caused by transmission of resistant micro-organisms from livestock, directly or through the environment. Reducing ESBL prevalence in livestock is expected to contribute to decreasing the health risks for humans.

- Undesirable side effects

A reduction of ESBL prevalence as such will not have negative side effects. On the contrary, the reduction may even improve the animal health status, in general.

\subsubsection{Results}

Prevalence of ESBLs in livestock has reduced in recent years as a consequence of reducing veterinary antibiotic use (MARAN, 2015). Figure 4.2 shows the prevalence of ESBL-producing E. coli at slaughter batch level in the past three years. Since the start of this surveillance programme in 2011, batch prevalence in pigs was highest in 2012 at $75 \%$ and decreased in 2013 to $57 \%$. In veal calves the batch prevalence decreased in 2013 from 70\% in 2011 and 2012 to 46\% in 2013. In individual dairy cows the prevalence seemed stable in 2012 and 2013 (between 7\% and 8\%). Currently, it is still unknown what the outcome of the current general ESBL measures will be (i.e., monitoring of ESBLS and the ban of specific antibiotics). Future sampling will reveal if the decreasing trends will continue.

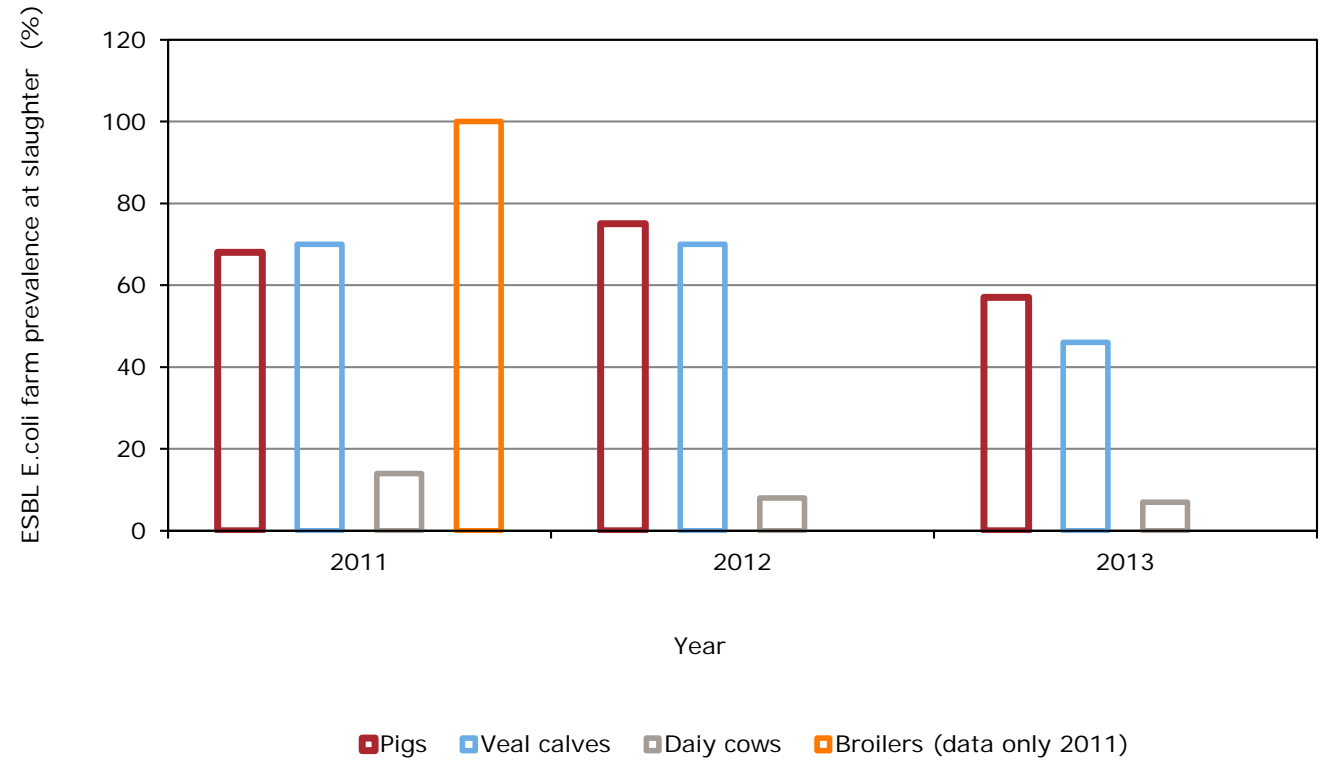

Figure 4.2 Results of policy decisions on ESBL (MARAN, 2015; Dierikx, 2014). 


\subsection{Recommendations future policy decisions ESBL}

When it comes to the choice of interventions, there is no easy solution. Instead, it is widely accepted that combinations of interventions are required to deal with the complexities of many policy issues (Murphy et al., 2012). Several interventions will be necessary to realise the objective of reducing ESBLS. The recommendations for future revisions of the ESBL policy in this paragraph are based on the revised and dynamic evaluation framework, as described in Section 3.8 and presented in Figure 4.3.

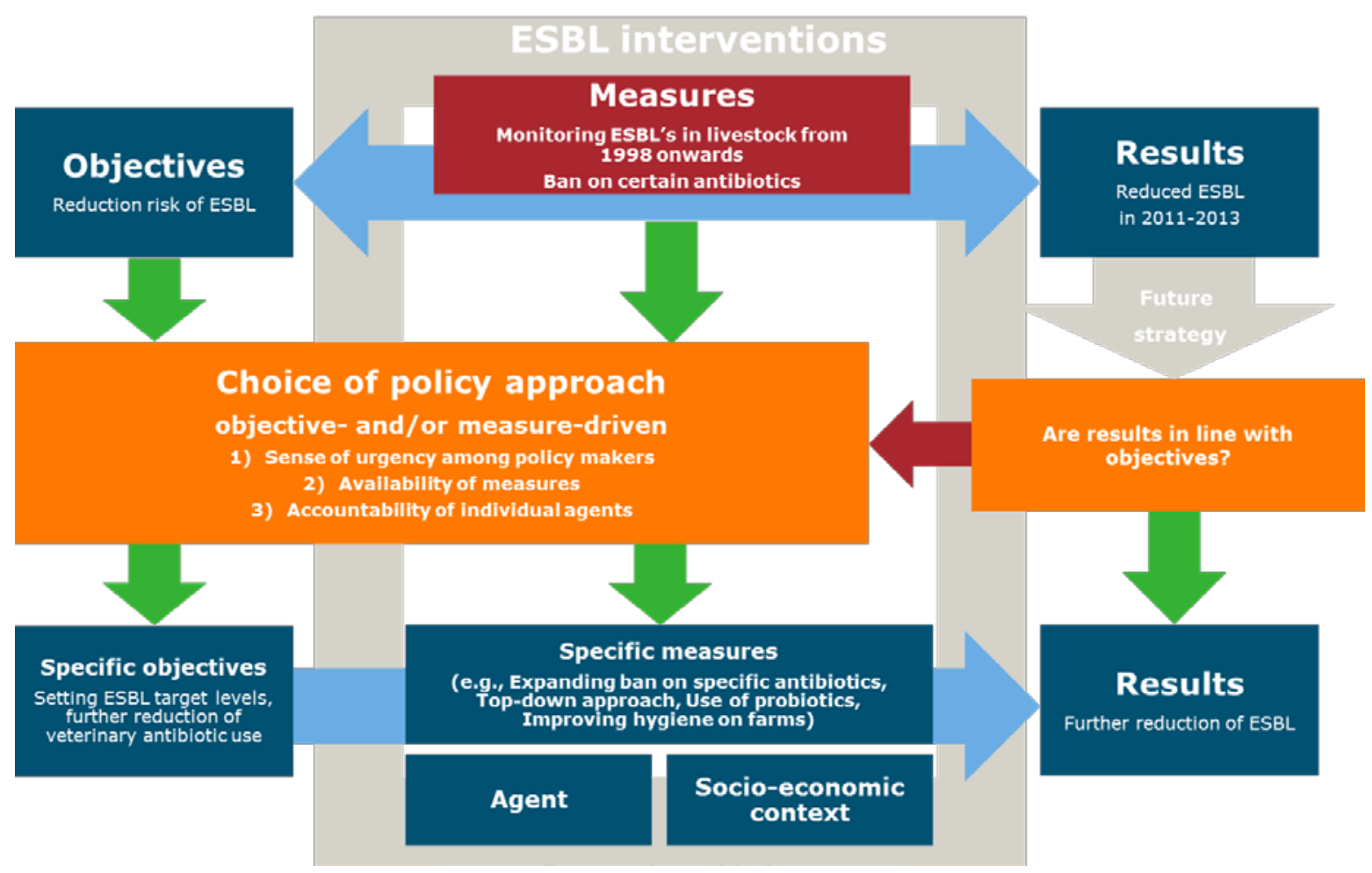

Figure 4.3 ESBL interventions within the evaluation framework.

\subsubsection{Current realisation of policy objectives}

The ESBL prevalence is decreasing, probably as a result of the reduced antibiotic use. It is unsure if this downward trend will continue. Moreover, it is unknown if the current decrease of ESBL prevalence will be sufficient from the viewpoint of human health risks.

\subsubsection{Objective-driven or measure-driven approach}

In general, safe food and a clean environment are needed to reduce ESBL-related human health problems, although many risk factors and transmission routes of ESBL to humans are still unknown. In those circumstances where not much is known about the infections and human health needs to be protected, the 'Precautionary Principle' is often used, in accordance with EU Regulation 178/2002: 'when (...) scientific information concerning the risk is inconclusive or incomplete in some way' provisional measures can be taken to protect health based on the precautionary principle, while seeking more complete scientific and other data ('better safe than sorry'). Thus, in principle, several additional measures might be feasible to realise the ultimate policy objective of 'improving human health'. For example, an intervention can aim to realise: a) an eradication programme to eliminate ESBLs ('search and destroy'); b) a top-down eradication programme; c) creating ESBL-free trade flows ('channelling') to increase food safety for specific high-risk groups; or d) implementing control measures aiming to reduce the overall level of ESBL-contamination. The policy objective to reduce 
ESBL 'option $c$ ' is in the coming years more feasible to be implemented than other two policy objectives.

In summary, a combination of setting clear objectives (and implementing a few additional measures, see Section 4.2.4) seems to be the most appropriate policy approach for the nearby future. The policy objectives regarding ESBL prevalence should be set on national level, because it is not or not yet feasible to measure results of individual stakeholders (e.g. farmers). Indirectly, a more stringent target for the reduction of veterinary antibiotic use could also be an objective. The advantage of a target on antibiotic use is that individual agents can be held accountable (additional measures could be focused on banning some other antibiotics that are related to ESBLs).

\subsubsection{Sense of urgency policy makers}

Regarding ESBLs, there is some sense of urgency among policy makers and other stakeholders, that something has to be done to reduce the risk of ESBLs. However, the urgency is still far from a crisis level. Not much is known about the sense of urgency in the agribusiness, especially among veterinarians and farmers. Now that ESBL levels are already substantially decreasing, probably as a result of the strongly reduced antibiotic use, the sense of urgency in the agribusiness might reduce quite quickly. On the other hand, new insights into the risks of ESBLs in livestock for the health of humans, or serious incidents, could very rapidly change the opinions of policy makers and other stakeholders affected.

\subsubsection{Availability of effective measures}

Most research on ESBLS and antimicrobial resistance has been aimed at the mechanisms of preventing occurrence and spread. Understanding the epidemiological efficacy is pivotal to successfully implement measures. The lack of scientific information complicates evaluating the epidemiological effectiveness of possible measures. However, several factors associated with the presence of ceftiofur resistence within (broiler) farms have been identified: avoiding the use of antibiotics (especially amoxicillin), hygiene, acidification of drinking water, feed changes, hatcheries, race, and bedding material (Persoons, 2010). I mportant measures are a reduction of veterinary antibiotic use, and infection control and hygiene on farms and in production chains. It is likely that measures aiming to reduce prevalence or to eradicate ESBLs will involve practices that will be implemented at farm level. Measures at farm level become only relevant if purchased animals are ESBL free. Therefore, a high-level analysis of these additional measures to control ESBL is described in terms of agent and socio-economic context in Table 4.1.

\section{Setting ESBL target levels in livestock}

The control of ESBLs could be implemented through the setting of target levels for the livestock sector in general or per subsector. This objective oriented approach could be similar to the policy that was used to reduce the veterinary use of antibiotics: setting an objective for the next two to four years and continuous monitoring of the results (i.e., by sampling the population). An important precondition is that there should be enough potential measures available for farmers to take action.

It is unsure whether there are effective measures available in the coming years. ESBL reduction seems to be much more difficult and uncertain than antibiotic use reduction (and other cases described in Chapter 3). But the setting of clear objectives as such will probably contribute to the awareness and the sense of urgency. Currently, there are several ongoing sector monitoring programmes. ${ }^{12}$ Monitoring on individual farm level would be ideal, similar to antibiotic use monitoring as from 20112012 onwards, but this will most probably be too expensive.

\footnotetext{
${ }^{12}$ There is even a monitoring for carbapenem resistance in livestock, that started in the Netherlands in 2012 and will be continued on all faecal samples of food-animals collected per year (approximately 1,500 per year).
} 
Further reduction of veterinary antibiotic use

Antibiotic use is considered to be the major factor involved in selection of ESBL-producing organisms.

Therefore the development of sustainable and healthy livestock production should continue to limit the need for antimicrobials use. However, it is not known to what extent this will solve the ESBL problem.

In livestock production antibiotic use was predominantly influenced by economic pressure and welfare concerns (Knowledge Agenda ESBL, 2014). Now the awareness of farmers of their responsibility to minimise antibiotic use has increased. But veterinarians and farmers will probably not be willing to further reduce the level of antibiotic use, in the coming years, because of the substantial reduction in use that has already been achieved. A further reduction of antibiotic use could seriously harm the technical and economical results of farms, and also have a negative impact on animal health, animal welfare and mortality.

Expanding ban on specific antibiotics

In the long term, an alternative should be found for the use of colistin in veterinary medicine. A ban was not feasible in the short term because colistin is the first choice drug in the treatment of certain animal diseases. The Committee of the Health Council also recommended to prohibit the use of third and fourth generation cephalosporins in group treatment of animals, also in the short term.

Top down approach

According to the Knowledge Agenda (2014) special attention should be given to prevention of transmission by contaminated animals through breeding pyramids (vertical transmission) or between production farms (horizontal transmission). A top-down approach to eradicate ESBLs is an option, just like it was for Salmonella control. In Salmonella, this approach has been very successful. However, the incentives to opt for this approach seem to be not as evident for ESBLs now, as they were for Salmonella 15 to 20 years ago. Especially the actual risks of ESBLs seem to be much lower than the risks of Salmonella-contaminated food.

It is doubtful if sufficient support can be found for this approach, because the sense of urgency is probably not high enough to take such far-reaching and costly measures. A further exploration of this option with respect to support by stakeholders in the chain is needed.

Use of probiotics

Probiotics will probably have an impact on the introduction and spread of ESBLs in broilers (see results of current experiment by CVI Wageningen UR).

Agent and socio-economic context. There are sufficient amount of probiotics available on the market. Already in 2012 thirty probiotics were registered in the EU for use in animal feed. ${ }^{13}$ The problem is that probiotics are generally expensive. Key question is to what extent the production will improve (e.g, less mortality, better growth and feed conversion, less use of antibiotics) to trade-off incurred treatment costs. If for example one treatment with the probiotic Aviguard costs approximately 2 eurocents per broiler (and discounting additional costs of labour for the spraying), and there are no clear benefits, this could reduce the income of a broiler farmer ( 8 eurocents per broiler) with almost $25 \%$. If more than one treatment would be necessary, the income reduction would even be $50 \%$ or higher.

\section{I mproving hygiene on farms}

According to the Knowledge Agenda (2014) strict implementation of on-farm external and internal biosecurity measures is needed to prevent introduction and spread of ESBL producing bacteria. Possible sources of introduction and/or spread of ESBLs are: purchased animals and animal contacts between and within production groups, feed, drinking water and other materials (bedding), pest animals, staff/visitors, bio-aerosols in incoming and/or circulating air and manure in animal houses/pens (hygiene).

$\overline{13 \text { https://zoek. officielebekendmakingen. nl/kst-29683-124.html }}$ 
Part of the livestock farmers is used to take strict hygiene measures, but probably a substantial amount of farmers does not want to take such strict measures, because it does not fit into the structure of their farm or in their style of management. Biosecurity measures can also be costly, but there are some benefits. Rojo-Gimeno et al. (2014) have analysed investments in internal and external biosecurity on closed pig farms. The technical results were better, including a $10 \%$ lower feed conversion and $0.7 \%$ lower mortality rates. Raising the score for external biosecurity with $4 \%$ costs a pig farm an estimated 1,500 euros a year. The cost of a more than $9 \%$ higher score for internal biosecurity amounted to more than 6,800 euros per year, mostly for animal health management. But the farms that took the recommended measures achieved a more than $12 \%$ higher gross margin, which suggests that interventions in biosecurity and management are economically viable. This can motivate farmers to adopt such measures. The findings of the high-level analysis are summarised in Table 4.1.

\section{Table 4.1}

High-level analysis of additional measures to control ESBL.

\begin{tabular}{|c|c|c|c|c|c|c|}
\hline & \multicolumn{2}{|l|}{ Objectives } & \multicolumn{4}{|l|}{ Measures } \\
\hline & $\begin{array}{l}\text { Setting } \\
\text { ESBL } \\
\text { target } \\
\text { levels in } \\
\text { livestock }\end{array}$ & $\begin{array}{l}\text { Further } \\
\text { reduction of } \\
\text { veterinary } \\
\text { antibiotic use }\end{array}$ & $\begin{array}{l}\text { Expanding } \\
\text { ban on } \\
\text { specific } \\
\text { antibiotics }\end{array}$ & $\begin{array}{l}\text { Top-down } \\
\text { approach }\end{array}$ & $\begin{array}{l}\text { Use of } \\
\text { probiotics }\end{array}$ & $\begin{array}{l}\text { Improving } \\
\text { hygiene on } \\
\text { farms }\end{array}$ \\
\hline $\begin{array}{l}\text { Agent } \\
\text { - Attitude } \\
\text { - Subjective norm } \\
\text { - Perceived behavioural control } \\
\text { Socio-economic context } \\
\text { - Cost-effectiveness on farm level } \\
\text { - Practical feasibility } \\
\text { - Relevance at sector level } \\
\text { - Societal impact } \\
\text { - Undesirable side effects }\end{array}$ & $\begin{array}{l}\text { Absence of } \\
\text { cost- } \\
\text { effective } \\
\text { measures. }\end{array}$ & $\begin{array}{l}\text { Substantial } \\
\text { reduction } \\
\text { already } \\
\text { achieved. }\end{array}$ & $\begin{array}{l}\text { Limited } \\
\text { scope. }\end{array}$ & $\begin{array}{l}\text { Far-reaching } \\
\text { and costly } \\
\text { measure. }\end{array}$ & $\begin{array}{l}\text { Will animal } \\
\text { production } \\
\text { improve to } \\
\text { trade-off } \\
\text { incurred } \\
\text { treatment } \\
\text { costs? }\end{array}$ & $\begin{array}{l}\text { Incentives to } \\
\text { adopt more } \\
\text { strict bio- } \\
\text { security } \\
\text { measures? }\end{array}$ \\
\hline
\end{tabular}

In summary, a pathway to revise the ESBL intervention strategy is to set one or more additional measures mandatory. The rational is that these specific measures are preferred by the decision maker because these are regarded as being effective and efficient. Especially reducing the use of antibiotics and banning some specific antibiotics seem to be effective measures to bring down ESBL levels. However, much is unknown about other potential relevant measures and thus underlying research questions have to be addressed first (i.e., which measures are effective and efficient, and what is the socio-economic context).

\subsubsection{Accountability of the individual agent}

An alternative pathway is to revise and specify the policy objectives. This seems to be appropriate, because in the case of ESBLs the relation between objectives and measures is unclear, effectiveness of measures is unknown, enforcement of measures may be difficult and the realisation of objectives is well measurable, at least on national level. When it comes to ESBL prevalence levels, the accountability of individual agents is difficult and costly.

The direct approach is to specify the ESBL target levels in livestock, while envisaged results can probably also be achieved indirectly by setting more stringent targets on veterinary antibiotic use. In this pathway farmers can opt which measure they will adopt, while in addition some measures might be set at sector level (e.g. stricter ban on certain antibiotics). 


\subsubsection{Agent}

To successfully implement interventions aiming to reduce or eliminate ESBLs besides attention for technical measures, attention should be focused to mechanisms that effectively change farmer's behaviour, so that they adopt the risk-reducing measures. Are the agents willing (attitude), pressed (subjective norm) and able (perceived behavioural control) to take adequate action? Incentive mechanisms, such as bonus or penalties appropriately used, regulation and training, facilitate a more successful implementation.

\subsubsection{Socio-economic context}

The socio-economic context needs to be assessed to distinguish criteria that either support or obstruct the implementing of certain measures. Cost-effectiveness on farm level, practical feasibility, relevance at sector level, societal impact, absence of undesirable side effects all determine the potential success of implementation. For example, a further reduction of veterinary antibiotic use might negatively affect the technical and economic results of farms or lead to impoverished animal welfare. 


\section{Conclusion and discussion}

\subsection{General evaluation framework}

Formulating a policy strategy starts with the question if the impacts are in line with the current policy objectives. If the results are not satisfactory, an adjustment of the policy is needed. The next step is to choose between an objective-driven or measure-driven approach or a hybrid approach, which depends on:

1. Sense of urgency among policy makers

2. Availability of measures

3. Accountability of individual agents.

The effectiveness of the policy largely depends on the agents and the socio-economic context:

\section{- Agents}

Are they willing (attitude), pressed (subjective norm) and able (perceived behavioural control) to take adequate action?

- Socio-economic context cost-effectiveness on farm level, practical feasibility, relevance at sector level, societal impact, undesirable side effects.

So, if a strategy for realising policy objectives consists of a specific set of technical measures, the socio-economic conditions should be optimised to stimulate implementing these measures. Per measure, the need for interventions could be assessed, based on a survey of the behavioural characteristics and personal preferences of the farmers. This part of the evaluation leads to 'tailormade' recommendations for implementation. Thus recommendations will be different for each group of farmers and/or other stakeholders, depending on which interventions are needed to stimulate the desired behaviour.

Different interventions will probably be needed for different agents (e.g. groups of farmers and other relevant stakeholders), depending on each group's specific socio-economic context. Not all measures are equally suitable to be implemented by all stakeholders, and the effectiveness of the implementation partly depends on stakeholders' socio-economic environment and circumstances. Motivating farmers on implementing behaviour aiming to maintain and preserve public goods most likely needs a different approach than motivating farmers in cases in which they perceive direct benefits. The exact mechanisms motivating farmers to implement behaviour aiming to preserve public goods and not to perceive individual benefits are still not fully understood. It is also currently not clear how these insights could lead to effective intervention strategies.

Although the presented socio-economic framework and its components are evident on a conceptual level, experience is lacking to adequately use this knowledge to design intervention strategies. Intervention strategies mostly focus on one measure only and are therefore most likely targeting only a selection of the population (and thus only a part of the desired result is achieved). A more integrated approach of multiple interventions is likely to reach a larger audience (e.g., livestock farmers across the sectors).

The described Revised Evaluation Framework could be developed further by adding aspects of the conditions for successful change (Ypma and Van Gaasbeek, 2001) and the 'Table of Eleven' (Dutch Ministry of J ustice, 2004).

According to Ypma and Van Gaasbeek (2001) the first important condition for a successful change is the 'sense of urgency': stakeholders should feel an increasing pressure to change. Other conditions are: clear common objectives, clear relationship between objectives and interventions, capacity to change, and a phased implementation of the foreseen interventions. 
The 'Table of Eleven' is a model based on behavioural sciences, consisting of eleven dimensions that influence the level of compliance with legislation. The instrument was developed by the Dutch Ministry of J ustice. For the evaluation framework especially the dimensions concerning spontaneous compliance can be relevant, such as knowledge of the rules, stakeholders' extent of acceptance and their respect for authority.

Some elements will probably overlap. For example, the 'sense of urgency' and the 'extent of acceptance' are already partly included in the 'attitude' of the agents. Other aspects will be complementary: e.g., the aspect 'knowledge of the rules' particularly stresses the importance of effective communication to the agents, which is not fully covered by the Theory of Planned Behaviour ('willing, pressed and able').

\subsection{ESBL evaluation framework}

An objective-driven policy approach is preferable since much is unknown about other potential relevant measures and moreover the accountability of individual agents is hampered, which are both requisites for a measure-driven policy approach (see Section 4.2 and Figure 4.3). Thus a combination of setting more clear and stringent objectives (i.e., maximum ESBL prevalence on national level) and implementing a few additional measures seems to be the most appropriate policy approach for the nearby future (see Section 4.2.4). Most prominent additional measures is to extend the ban of some other antibiotics that are related to ESBLs.

Indirectly, a more stringent target for the reduction of veterinary antibiotic use could also support the ESBL reducing objective. The advantage of a target on antibiotic use is that individual agents can be held accountable.

Understanding the epidemiological efficacy is pivotal to successfully implement measures. The lack of scientific information complicates evaluating the epidemiological effectiveness of possible measures. Further research is required to evaluate all potential measures from an epidemiological point of view.

It is likely that measures aiming to reduce prevalence or to eradicate ESBLs will involve practices that will be implemented at farm level. Therefore, to successfully implement interventions aiming at a reduction or elimination of ESBLs besides attention for technical measures, attention should be given to mechanisms that effectively change farmer's behaviour (so that risk-reducing measures are adopted by them). Cost-effectiveness on farm level, practical feasibility, relevance at sector level, societal impact, absence of undesirable side effects and the behavioural characteristics of agents involved all determine the potential success of implementation. Incentive mechanisms like bonus or penalties intelligently used, regulation and training facilitate a successful implementation.

The ESBL prevalence has recently been decreasing, however it is unsure if this downward trend will continue with the current policy implemented. Moreover, it is unknown if the current ESBL prevalence levels addresses the sense of urgency sufficiently from the viewpoint of human health risks. 


\section{References and websites}

Ajzen, I., 1991. The theory of planned behavior. Organizational Behavior and Human Decision Processes, 50, 179-211.

Asseldonk, M.A.P.M. van, J. Prins en R.H.M. Bergevoet, 2013. Economic assessment of Q fever in the Netherlands. Preventive Veterinary Medicine, 112, 27-34.

Beedell, J.D.C. en T. Rehman, 2000. Using social-psychology models to understand farmers' conservation behaviour. Journal of Rural Studies 16, 117-127.

Bergevoet, R.H.M., C.J.M. Ondersteijn, H.W. Saatkamp, C.M.J . van Woerkum, R.B.M. Huirne, 2004. Entrepreneurial behaviour of Dutch dairy farmers under a milk quota system: Goals, objectives and attitudes. Agricultural Systems 80, 1-21.

Bontje, D.M., J.A. Backer, H.I.J. Roest, M.A.P.M. van Asseldonk, R.H.M. Bergevoet en H.J.W. van Roermund, 2013. Control measures against $Q$ fever in Dutch dairy goat herds: epidemiological and economical evaluation. Wageningen University.

Bouwknegt, M., I. Friesema, M.J. Mangen, W. van Pelt en A. Havelaar, 2015. De ziektelast van voedselgerelateerde infecties in Nederland, 2009-2012. RI VM, Bilthoven.

Breukers, A., M.A.P.M. van Asseldonk, J. Bremmer en V. Beekman, 2012. Understanding grower's decisions to manage invasive pathogens at the farm level. The American Phytopathological Society, volume 102, no 6, 609-619.

Breukers, A., P. de Wolf, R. Slobbe, L. Molendijk, 2013. Duurzaam fytosanitair bodembeheer. Naar een betere beheersing van schadelijke organismen in Nederlandse landbouwgrond. LEI report 2013-011. The Hague, January 2013.

Bruschke, C.J.M., H.I.J. Roest and R.A. Coutinho, 2015. Q fever: the Dutch policy. Journal of Risk Research. DOI: 10.1080/13669877.2015.1042498.

Bunte, F. en P. Diederen, 2004. Behaviour, Institutions and Policy.

Colémont, A., S. van den Broucke, 2008. Measuring determinants of occupational health related behvior in Flemish farmers: an application of the Theory of Planned Behaviour. J ournal of Safety Research 39, 55-64.

DG Sante, 2015. Evaluation of the Commission's Communication to the European Parliament and the Council on the Action Plan against the rising threats from Antimicrobial Resistance (AMR) (COM (2011) 748).

Dierikx, C., J. van der Goot, T. Fabri, A. van Essen-Zandbergen, H. Smith en D. Mevius, 2013. Extended-spectrum- $\beta$-lactamase- and AmpC- $\beta$-lactamase-producing Escherichia coli in Dutch broilers and broiler farmers. J ournal of Antimicrobial Chemotherapy 201368 (1): 273-278.

Dutch Ministry of Justice, 2004. The 'Table of Eleven'. A versatile tool. Ministry of J ustice, Law Enforcement Expertise Centre, The Hague.

EFSA, 2011. Scientific Opinion on the public health risks of bacterial strains producing extendedspectrum bèta-lactamases and/or AmpC bèta-lactamases in food and food-producing animals. EFSA J ournal 9(8): 2322;47, 2011. 
Fielding, K.S., D.J. Terry, B.M. Masser, M.A. Hogg, 2008. Integrating social identity theory and the theory of planned behaviour to explain decisions to engage in sustainable agricultural practices. British J ournal of Social Psychology 47, 23-48.

Hoek, W. van der, F. Dijkstra, B. Schimmer, P.M. Schneeberger, P. Vellema, C. Wijkmans, R.T. Schegget, V. Hackert en Y. van Duynhoven, 2010. 'Q fever in the Netherlands: an update on the epidemiology and control measures.' Eurosurveillance 15(12): 1-4.

Hogerwerf, L., R. van den Brom, H.I. Roest, A. Bouma, P. Vellema, M. Pieterse, D. Dercksen, M. Nielen, 2011. 'Reduction of coxiella burnetii prevalence by vaccination of goats and sheep, The Netherlands.' Emerging Infectious Diseases 17(3): 379-386.

Hopster, H., 2010. Dierenwelzijn: geen hype, maar blijvende transitiedriver. In; Over zorgvuldige veehouderij. Veel instrumenten, één concert. Wageningen University.

Huij bers P.M., M. de Kraker, E.A. Graat, A.H. van Hoek, M.G. van Santen, M.C. de Jong, E. van Duijkeren, en S.C. de Greeff, 2013. Prevalence of extended-spectrum $\beta$-lactamase-producing Enterobacteriaceae in humans living in municipalities with high and low broiler density. Clin Microbiol I nfect. 2013 Jun; 19(6):E256-9. doi: 10.1111/1469-0691.12150. Epub 2013 Feb 11.

Jimmink, B.A., P.W.H.G. Coenen, R. Droge, G.P. Geilenkirchen, A.J. Leekstra, C.W.M. van der Maas, R.A.B. te Molder, C.J. Peek, J. Vonk en D. Wever, 2014. Emissions of transboundary air pollutants in the Netherlands 1990-2013. RIVM Report 2014-0166.

Lauwere, C.C. de, M.A.P.M. van Asseldonk, J.P. van 't Riet, J.G. de Hoop en E. ten Pierick, 2012. Understanding farmers' decisions with regard to animal welfare: The case of changing to group housing for pregnant sows. Livestock Science 143 (2-3), 151 - 161.

Maassen, K., A. de Jong, O. Stenvers, S. Valkenburgh, I. Friesema, K. Heimeriks, W. van Pel en H. Graveland, 2012. Staat van zoönosen 2011. RIVM, Bilthoven.

MARAN, 2015. Monitoring of Antimicrobial Resistance and Antibiotic Usage in Animals in the Netherlands in 2014. http://www.wageningenur.nl/upload_mm/2/2/2/0ab4b3f5-1cf0-42e7-a460d67136870ae5_NethmapMaran2015.pdf.

Melse, R.W., N.W.M. Ogink en W.H. Rulkens, 2009. Overview of European and Netherlands' regulations on airborne emissions from intensive livestock production with a focus on the application of air scrubbers. Biosystems Engineering, 104 (3) (2009), pp. 289-298.

Meuwissen, M.P.M., T.T. Assefa en M.A.P.M. van Asseldonk, 2013. Insurance in European Agriculture: Experience of Mutuals in the Netherlands. EuroChoices 12(3), 10-16.

Meuwissen, M.P.M., M.A.P.M. van Asseldonk en R.B.M. Huirne, 2003. Alternative risk financing instruments for swine epidemics. Agricultural Systems, 75, 305-322.

Murphy, L., F. Meijer en H. Visscher, 2012. A qualitative evaluation of policy instruments used to improve energy performance of existing private dwellings in the Netherlands. Energy Policy, 1-11.

Persoons, D., F. Haesebrouck, A. Smet, A., L. Herman, M. Heyndrickx, A. Martel, B. Catry, A.C. Berge, P. Butaye en J. Dewulf, 2010. Risk factors for ceftiofur resistance in Escherichia coli from Belgian broilers. Epidemiol Infect. 139:765-771.

Roest, H.I.J., J.J.H.C. Tilburg, W. van der Hoek, P. Vellema, F.G. van Zijderveld, C.H.W. Klaassen en D. Raoult, 2011. 'The Q fever epidemic in the Netherlands: History, onset, response and reflection.' Epidemiology and Infection 139(1): 1-12. 
Rojo-Gimeno, C., M. Postma, J. Dewulf, H. Hogeveen en E. Wauters. Farm economic analysis of improving biosecurity status and management in farrowing-to-finishing pig farms. NJF seminar Economics of Animal Health and Welfare, 15th May 2014.

http:// pure.ilvo.vlaanderen.be/ portal/files/3154024/Rojo_NJF_2014_Farm_economic_analysis_of_ improving_biosecurity_status.pdf

PVE, 2012. Hygiënecode Eieren voor Verzamelaars, Pakstations en Grossiers. Zoetermeer.

Schimmer, B., F. Dijkstra, P. Vellema, P.M. Schneeberger, V. Hackert, R.T. Schegget, C. Wijkmans, Y. van Duynhoven en W. van der Hoek, 2009. 'Sustained intensive transmission of IQ fever in the south of the Netherlands, 2009.' Eurosurveillance 14(19): 1-3.

Starmans, D.A.J. en K.W. van der Hoek, 2007. Ammonia, the case of the Netherlands. Wageningen Academic Publishers.

Tamminga, S., 1992. Gaseous pollutants produced by farm animal enterprises. In: C. Phillips and D. Piggins, Farm Animals and the Environment. C.A.B. International, p. 345-357.

Tempelman, C., J. Prins en C. Koopman, 2011. Economic consequences of the Q-fever outbreak. Amsterdam, SEO Economisch Onderzoek.

Ypma, M.E. en A.F. van Gaasbeek, 2001. (Im)possibilities of marketing of the environment ('Waar in het bronsgroen eikenhout...; (On)mogelijkheden van vermarkting van de omgeving'). LEI report 7.01.05. The Hague, 2001. In Dutch.

http://wwww. adiveter.com/ftp_public/articulo1812. pdf. Total Surveillance of Animal Production. IKB: triple quality assurance.

\section{Experts consulted}

The following experts of Wageningen UR were consulted:

Monique van der Gaag

Peter van Horne

Hans Hopster

Dik Mevius

Hendrik-J an Roest

Nico Verdoes 
LEI Wageningen UR

\section{P.O. Box 29703}

2502 LS The Hague

The Netherlands

$\mathrm{T}+31$ (0)7033583 30

E publicatie.lei@wur.nl

www.wageningenUR.nl/en/lei

REPORT

LEI 2016-020
LEI Wageningen UR is one of the world's leading independent socio-economic research institutes. LEl's unique data, models and knowledge offer clients insight and integrated advice on policy and decision-making in an innovative manner, and ultimately contribute to a more sustainable world. LEI is part of Wageningen UR (University and Research centre), forming the Social Sciences Group together with the Department of Social Sciences and Wageningen UR Centre for Development Innovation.

The mission of Wageningen UR (University \& Research centre) is 'To explore the potential of nature to improve the quality of life'. Within Wageningen UR, nine specialised research institutes of the DLO Foundation have joined forces with Wageningen University to help answer the most important questions in the domain of healthy food and living environment. With approximately 30 locations, 6,000 members of staff and 9,000 students, Wageningen UR is one of the leading organisations in its domain worldwide. The integral approach to problems and the cooperation between the various disciplines are at the heart of the unique Wageningen Approach. 


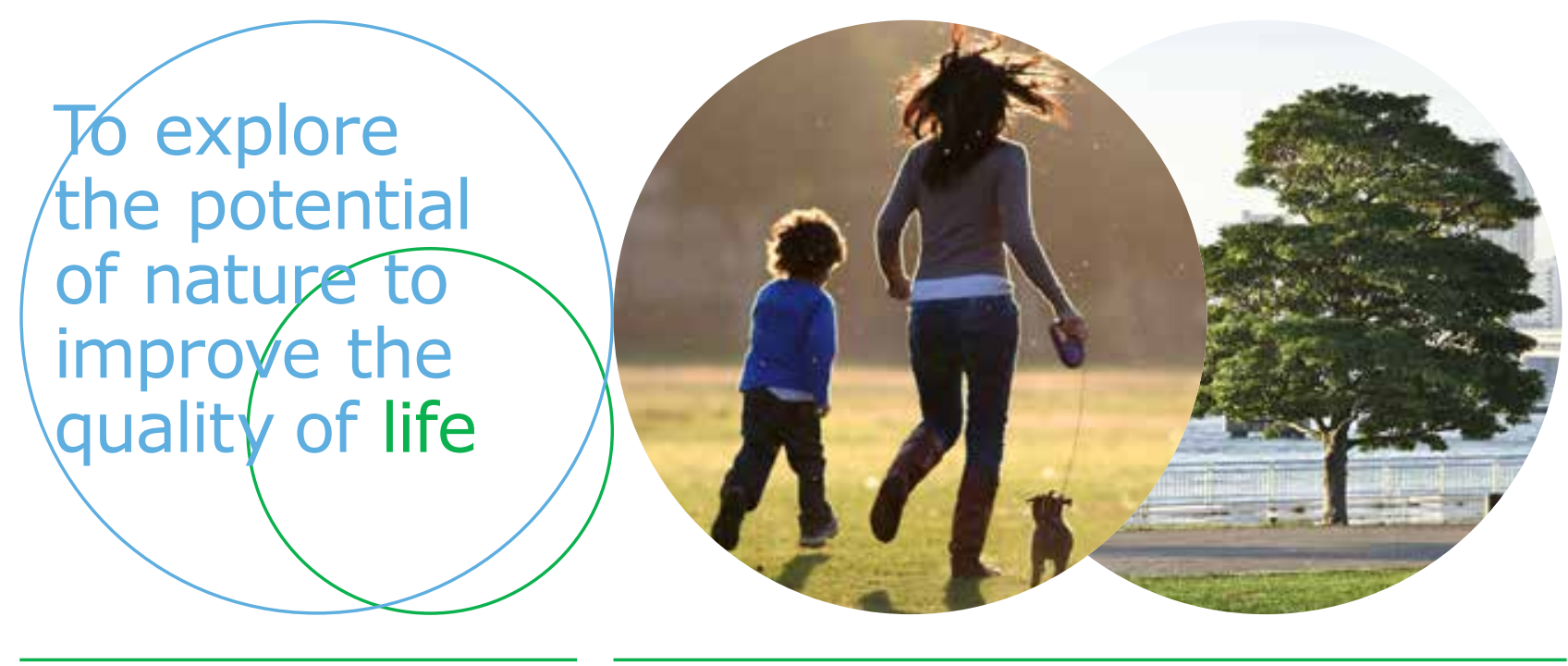

LEI Wageningen UR

P.O. Box 29703

2502 LS Den Haag

The Netherlands

E publicatie.lei@wur.nl

www.wageningenUR.nl/lei

REPORT

LEI 2016-020

ISBN 978-94-6257-851-7
LEI Wageningen UR is one of the world's leading independent socio-economic research institutes. LEI's unique data, models and knowledge offer clients insight and integrated advice on policy and decision-making in an innovative manner, and ultimately contribute to a more sustainable world. LEI is part of Wageningen UR (University and Research centre), forming the Social Sciences Group together with the Department of Social Sciences and Wageningen UR Centre for Development Innovation.

The mission of Wageningen UR (University \& Research centre) is 'To explore the potential of nature to improve the quality of life'. Within Wageningen UR, nine specialised research institutes of the DLO Foundation have joined forces with Wageningen University to help answer the most important questions in the domain of healthy food and living environment. With approximately 30 locations, 6,000 members of staff and 9,000 students, Wageningen UR is one of the leading organisations in its domain worldwide. The integral approach to problems and the cooperation between the various disciplines are at the heart of the unique Wageningen Approach. 